Below is an unedited, uncorrected BBS Target Article recently accepted for publication. This preprint has been prepared specifically for potential commentators who wish to nominate themselves for formal commentary invitation via Editorial Manager: http://bbs.edmgr.com/. The Commentary Proposal Instructions can be accessed here: http://journals.cambridge.org/BBSJournal//nst/Call

Please DO NOT write a commentary unless you receive a formal email invitation from the editors. If you are invited to submit a commentary, a copyedited, corrected version of this paper will be made available.

\title{
Toward a second-person neuroscience
}

\author{
Leonhard Schilbach \\ Bert Timmermans \\ Vasudevi Reddy \\ Alan Costall \\ Gary Bente \\ Tobias Schlicht \\ Kai Vogeley
}

Corresponding author: Leonhard Schilbach, leonhard.schilbach@nf.mpg.de Max-Planck-Institute for Neurological Research, Cologne, Germany

\begin{abstract}
In spite of the remarkable progress made in the burgeoning field of social neuroscience, the neural mechanisms that underlie social encounters are only beginning to be studied and could — paradoxically — be seen as representing the 'dark matter' of social neuroscience. Recent conceptual and empirical developments consistently indicate the need for investigations, which allow the study of real-time social encounters in a truly interactive manner. This suggestion is based on the premise that social cognition is fundamentally different when we are in interaction with others rather than merely observing them. In this article, we outline the theoretical conception of a second-person approach to other minds and review evidence from neuroimaging, psychophysiological studies and related fields to argue for the development of a second-person neuroscience, which will help neuroscience to really go social; this may also be relevant for our understanding of psychiatric disorders construed as disorders of social cognition.
\end{abstract}

Keywords: mentalizing network; mirror neuron system; social cognition from an interactor's point of view; social cognition from an observer's point of view; 'problem' of other minds; second-person neuroscience 
"No more fiendish punishment could be devised, were such thing physically possible, than that one should be turned loose in society and remain absolutely unnoticed."

William James (1890), The Principles of Psychology.

\section{Introduction}

The burgeoning field of social neuroscience has begun to illuminate the complex biological bases of human social cognitive abilities (Frith \& Frith 2010; Ochsner \& Lieberman 2001). Many investigations have focused, in particular, on the neural correlates of our capacity to grasp the mental states of others. Two neuroanatomically distinct large-scale networks have gained center stage as the neural substrates of social cognition: the so-called "mirror neuron system" (MNS) and the "mentalizing network" (MENT). The former has been taken as evidence for a simulationist account of social cognition and is believed to give us a "first-person grasp" of the motor goals and intentions of other individuals (Rizzolatti \& Sinigaglia 2010). The latter has been seen as providing evidence for a "Theory Theory" account of social cognition believe to give us an inferential, reflective (and what might be called a 'third-person') grasp of others' mental states (Frith \& Frith 2006, 2010). The apparent disparity between these sets of results may, however, arise from differences in the experimental paradigms used (cf. Keysers \& Gazzola 2007), which run the danger of presupposing the very theoretical frameworks they claim to test. Consequently, both of these paradigms are investigating actual, but limited domains of social cognition. Both are, in effect, committed to spectator theories of knowledge. They have focused on the use of "isolation paradigms" (Becchio et al. 2010), in which participants are required to merely observe others or think about their mental states rather than participate in social interaction with them. Consequently, it has remained unclear whether and how activity in the large-scale neural networks described above is modulated by the degree to which a person does or does not feel actively involved in an ongoing interaction and whether the networks might subserve complementary or mutually exclusive roles in this case (Schilbach 2010). After more than a decade of research, the neural mechanisms underlying social interaction have remained elusive and could — paradoxically — be seen as representing the 'dark matter' of social

\footnotetext{
1 In sensu strictu, the term dark matter is used in physics and astronomy to describe matter, which is inferred to exist, but which has not been directly observed and may not even be observable. We use the term metaphorically to denote an important lacuna in current areas of research in social neuroscience, which have been more difficult to investigate and where, therefore, less is known, but which can at least in principle be explored empirically. To index this particular usage of the term, 'dark matter' is consistently used in inverted commas throughout the paper.
} 
neuroscience.

In this target article we propose an approach to the investigation of social cognition focused on 'second-person' engagements. This approach, we argue, will help to throw light on this 'dark matter' and may help social neuroscience to really go social.

\subsection{Spectator Theories of Other Minds}

Spectatorial accounts of social knowing are not restricted to social neuroscience, but have been central to the Western intellectual tradition (Dewey 1950). Psychological accounts of how people make sense of other people have usually shared a common format:

Each is a detached observer, rather than actively engaged with the other in some joint project.

The information available to each of us about other people is limited and disorganized, and hence there is a gulf between what we can actually observe about them, and what they themselves feel, intend, or believe.

Each of us, therefore, has to engage in some or other intellectual 'detour' to bridge the gap between what can be immediately experienced about the other person and that person's psychological states (see Asch 1952).

As Neisser has pointed out, this detached and intellectualist theoretical approach to how people make sense of one another has been built into the research which was supposed to support that very position: namely, people observing video-recordings of other people, and making judgments of what they saw:

The theories and experiments ... all refer to an essentially passive onlooker, who sees someone do something (or sees two people do something) and then makes a judgment about it. He ... doesn't mix it up with the folks he's watching, never tests his judgments in action or interaction. He just watches and makes judgments. [...] When people are genuinely engaged with one another, nobody stops to give grades (Neisser 1980, pp.603-4). 
Modern cognitive psychology has retained "methodological behaviorism" from precisely the psychology it claims to have undermined (see Costall 2006; Garner 1999; Jenkins 1986; Leahey 1992; Neisser 1997). According to the textbooks, psychologists in their research necessarily start from the observation of inherently meaningless, "colorless behavior" (Hull 1943, p.25) and can only begin to make psychological sense of what they observe on the basis of theorizing. Few modern psychologists, of course, are Cartesian dualists: they rightly insist that they do not make an ontological disjunction between behavior and mind.

Nevertheless, psychologists keep framing their methodology, in principle if not in their actual practice, in the old Hullian, reductionist terms, and hence keep talking themselves into a methodological dualism of behavior and mind. In so doing, they resurrect for themselves the traditional dualistic 'problem' of other minds. And, when Theory Theorists project this methodology onto other people and how they make sense of one another, they often enough also carry the same insoluble problem with them. In relation to the other domains to which it has been applied, the "Theory Theory" approach has taken for granted that the child has already acquired a substantial practical understanding of the social domain before attempting to systematize his or her existing knowledge (such as friction or collisions in the domain of physics, and reproduction and growth in the domain of biology). This is not the case for "Theory Theory" of Mind (TToM) in its original form, for, according to TToM, it is only once children have developed a "Theory of Mind" that they have access to any of the necessary psychological data upon which the theory could be based.

Of course, "Theory of Mind" does not refer to a theory in the scientific sense, but denotes an empirical field of study with (apparently) no particular theoretical commitments (cf. Penn \& Povinelli 2008, p.394). Yet to the extent that the most important alternative approach, "Simulation Theory", frames the problem of how people make sense of other people in terms of how psychologists make a detour from the observation of 'mere' behavior to psychological states they both face the same logical impasse. Indeed, there could be no naturally occurring precursors to "Theory of Mind", not even evolved ones, if the problem of how we really make sense of one another is framed in terms of this kind of methodological dualism (see Costall et al. 2006; Leudar \& Costall 2008). 


\subsection{An alternative account of social knowing}

Before the rise of recent social cognition research there was already an important body of theory and research proposing that, typically, when relating to one another, people are not engaged in a tortuous process of inferences and theorizing about one another, but immediately experience the other as a subject (see Asch 1952; Heider \& Simmel 1944; Runeson \& Frykholm 1983; Schutz 1972; Thinès et al. 1991). This approach drew upon Gestalt theory and phenomenology. Here is Solomon Asch's lucid statement of this position:

The quality of their actions imbues persons with living reality. When we say that a person is in pain, we see his body as feeling. We do not need to 'impute' consciousness to others if we directly perceive the qualities of consciousness in the qualities of action. Once we see an act that is skillful, clumsy, alert, or reckless, it is superfluous to go 'behind' it to its conscious substrate, for consciousness has revealed itself in the act (Asch 1952, p.158).

This social perception approach is close to the theoretical perspective we are presenting in this target article. It is not detached; it is not dispassionate. However, it is, nevertheless, committed to an observer epistemology, a spectator theory of how we relate to other people. Knowing others is limited to perceiving them. In this target article, we will be arguing for an approach to social knowing based on interaction and emotional engagements between people, rather than mere observation. This 'second-person' approach has already begun to prove productive within developmental and social psychology and points toward the importance of experiencing and interacting with others as our primary ways of knowing them (see Section 2 for details). Also, preliminary evidence from neuroimaging and psychophysiological studies demonstrates profound differences in neural processing related to the reciprocity of social interaction, which is consistent with our proposal that the second-person approach can make an important contribution to the neuroscientific study of social encounters and could, in fact, lead to the development of a secondperson neuroscience (Section 3). In this respect, we provide an outlook for future research by describing key ideas and objectives of a second-person neuroscience and related objectives in other areas of research (Section 4). Finally, we argue that the second-person account may also be relevant for our understanding of psychiatric disorders: While psychiatric disorders such as 
autism have been conceptualized as disorders of explicit social cognition, recent evidence suggests that the implicit processes of interpersonal coordination relevant during second-person engagements might be more closely related to the core impairments (Section 5). 


\section{Second-Person Engagements}

\subsection{Overcoming the Spectatorial Gap}

Spectatorial views of cognition have been developed within the paradigm of standard cognitive science, which understands cognition as information processing in the sense of a passive intake of information provided by a ready-made world. Embodied cognition replaces this view by a concept in which perception is seen as an active process executed by an organism situated in the environment the subjects of which are not isolated from but embedded and coupled in the perceived world (Thompson 2007). Such coupling brings to the fore new properties — what Gibson (1979) calls "affordances"- which depend on the organism's specific potential and actual interaction with the environment. In this way, cognition is essentially construed as an activity carried out by an embodied and embedded agent. In addition to hybrid accounts of “Theory Theory" and "Simulation Theory" (e.g., Goldman 2006; see Newen \& Schlicht 2009 for a critical discussion), recent debates have, therefore, led to alternatives, which emphasize various aspects of embeddedness and embodiedness in social cognition (De Jaegher \& Di Paolo 2007; Fuchs 2009; Gallagher 2005, 2008; Hutto 2008; Noë 2009; Reddy 2008; Zahavi 2005).

Spectatorial views construe social cognition as something that could in principle occur in the presence of a one-way mirror, where a detached observer reads out the mental states of another person, who, in turn, is not affected by this and cannot react to it. In contrast to this, our central claims are that social cognition is fundamentally different when (2.1.1) we are emotionally engaged with someone as compared to adopting an attitude of detachment and when (2.1.2) we are in interaction with someone as compared to merely observing her (Figure 1 A - D). 


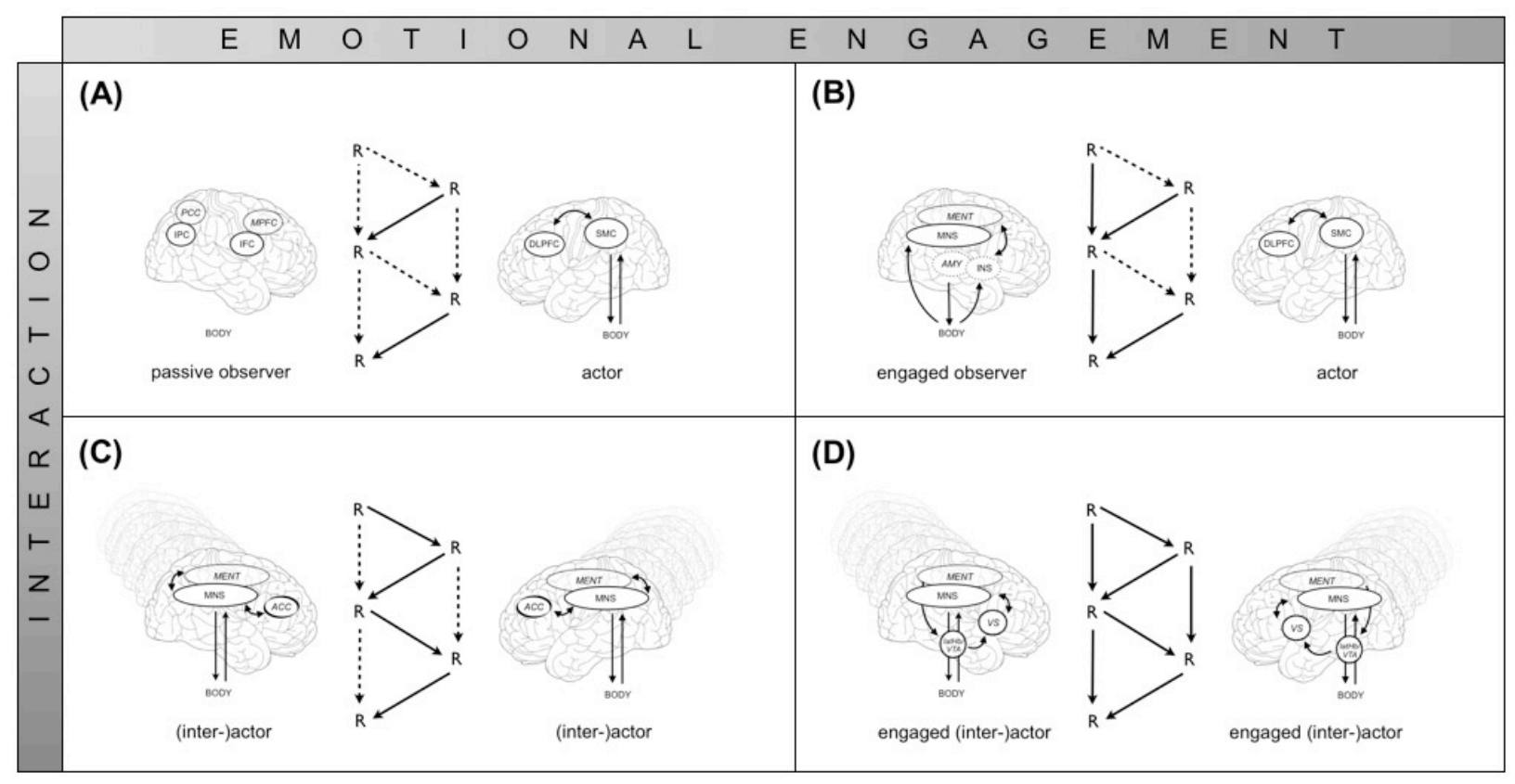

Figure 1. 


\section{Legend:}

\section{Figures 1 A-D:}

Center: Schematic depiction of interaction contingencies for situations of (A) no (or little) social interaction and no (or little) emotional engagement, (B) no (or little) social interaction, but emotional engagement of person A with person B, (C) social interaction, but no (or little) emotional engagement and (D) social interaction and emotional engagement. Dotted lines indicate the absence or relatively decreased influence of actions on oneself (vertical arrows) or the other (oblique arrows), temporal sequence is shown from top to bottom (schematic of interaction contingences adapted from: Jones \& Gerard 1967). Despite the suggestion of linearity in the interaction sequence, our account also stresses the importance of interaction dynamics, which may be seen as emergent properties of an interaction, and possible inter-brain effects of social interaction (see section $2.3 \& 3.2 .2$ for details).

Left $\&$ right: Schematic depiction of putative differences in the recruitment of brain regions during situations A-D and their functional connectivity (see Section 3 for details). Brain regions on the medial surface or deep structures of the brain are shown in italics, brain regions on the lateral surface of the brain are shown in normal font.

Abbreviations: R: (re-) actions performed by agents. MENT: The "mentalizing network" is a network of brain regions recruited by tests, which tap "the ability to read the desires, intentions, and beliefs of other people“ (e.g. Frith \& Frith 2008). In line with recent meta-analyses of functional neuroimaging studies, which have investigated mentalizing, we see medial prefrontal cortex (MPFC) and the posterior cingulate cortex (PPC) as the most important nodes of this network, sometimes also referred to as the "cortical midline structures" (e.g. Northoff \& Bermpohl 2004; Schilbach et al. in press; Uddin et al. 2007). While a large body of literature exists to suggest that these brain regions can be differentially engaged by classical mental state attribution tasks (Figure 1A), much less is known about the interactions within this network and with other brain regions as a function of emotional engagement and social interaction (Figure 1B-D). MNS: As introduced in section 1 the so-called "mirror neuron system" is thought to include areas of inferior frontal cortex (IFC) and inferior parietal cortex (IPC) (Rizzolatti \& Sinigaglia 2010). Individual nodes of this network are known to become active during the observation of goal-directed actions, but their interplay and, in particular, the interaction with MENT is not well understood (Figure 1B-D; Schilbach 2010). SMC: Primary sensorimotor cortex. DLPFC: Dorsolateral prefrontal cortex (separate from MNS regions). $\boldsymbol{A C C}$ : Anterior cingulate cortex (here thought to be separate from MENT). $\boldsymbol{A M Y}$ : Amygdala. INS: Insular cortex. LatHb: Lateral habenula complex. VTA: Ventral tegmental area. VS: Ventral striatum. 


\subsubsection{Constituents of a second-person approach: Emotional engagement}

A second-person grasp of other minds, we argue, is, first, closely related to feelings of engagement and emotional responses to the other. According to this viewpoint, awareness of other minds crucially hinges upon emotional engagement and a responsiveness to another person's states or actions as compared to a detached observer's attitude, which does not include such responding (cf. Reddy 2003, 2008; Rietveld 2008; Figure 1). Although emotional responses are also influenced by one's own concerns, they constitute an important way of perceiving and integrating the state of the other by way of experiencing one's own bodily responses to her (e.g. Prinz 2003; Figure 1B). Mentality - in this view - is thought to become meaningful as a result of relating new pieces of experience to a pre-existing network of experiences. On a neural level, emotional and embodied responses may play a crucial role in influencing action control networks of the brain by modulating processes of sensorimotor integration, which, in turn, solicit activity and observable behavior (Frijda 1986, p.469; Keltner \& Haidt 1999; Schilbach et al. 2008a; Figure 1). Consequently, affective responses relying upon proprioceptive afferences from the body and action-based processes are likely to be closely linked and to interact in complex ways. For instance, it would seem plausible that emotional-embodied responses could facilitate more cognitive ways of understanding minds, while the absence of such responses could make this a more effortful process. Furthermore, it is important to point out that while emotional engagement may also occur (and could be particularly relevant) during observation (such as watching an emotionally charged movie scene or perceiving to be perceived by someone, Figure 1B), the opposite may be true for some situations, in which one actually interacts with someone (such as hastily buying a bus ticket from a cashier, Figure 1C).

\subsubsection{Constituents of a second-person approach: Social interaction}

Second, we see social interaction as a key constituent of grasping other minds. Social interactions are characterized by intricate reciprocal relations with the perception of socially relevant information prompting (re-) actions, which are themselves processed and reacted to (Figure $1 \mathrm{C} \& \mathrm{D}$ ). These reciprocities might be sequential (as depicted in the schematic of Figure 1), but are often complex, dynamic and non-linear (Froese \& Di Paolo 2010; Port \& van Gelder 1995; Thelen \& Smith 1994). Being in interaction with someone, we suggest, furthermore relies upon a perception of the environment in terms of the resources held collectively by both interactors rather than those held by each individual alone (Costall 1995; Sebanz et al. 2006; 
Richardson et al. 2007; Marsh et al. 2009; Schilbach et al., in press). In social interaction rather than exercising one's deliberative reflective capacities we exercise our own practical know-how in dealing with others as interactors (Klin et al. 2003). Here, interaction and feedback are not only a way of gathering data about the other person, i.e. observing effects one may have on the other, but rather, as De Jaegher et al. (2010) have argued persuasively, one's knowledge of the other resides - at least in part - in the interaction dynamics 'between' the agents. Thus, taking social interaction seriously suggests that there may not be an absolute epistemic gulf between self and other, which would make an inferential detour necessary, but rather that the dynamics of the social interaction contribute to and - at times - constitute our awareness of other minds (Figure $1 \mathrm{C} \& \mathrm{D})$.

There are at least three different aspects of social interaction, which are important for research in social neuroscience. First, interaction involves different roles for the interactors. At the simplest level, one can be an 'initiator' or a 'responder' in an interaction, i.e. the same (or very similar) action can be performed in an attempt to initiate an interaction or as a response to someone else's action. Although such a simple and clear-cut difference in roles may be rare in dynamic real-time encounters, we believe that this distinction is important for neuroscience research, because it implies different motivational consequences and differences in the underlying neural processes: An action by an 'initiator' may involve stronger monitoring of the outcome of the interaction, while an action by a 'responder' may involve closer attention to the emotional effects of the action being responded to, a difference which may be reflected in differential involvement of brain regions (see Figure 1). Second, shared intentions and motivations are newly created within interaction, with important consequences for the performance of joint actions and for the progress and continuation of the interaction itself. We argue that these processes are quite different from those involved in merely observing someone else interact, and must play a crucial role in shaping activity in the neural networks that underlie social cognition (see section $3 \& 5$ for further details). Third, interaction always involves historicity suggesting that social phenomena must be understood - at both the psychological and the neural level — within the context of the past and must involve developmental trajectories, which continue to be relevant throughout the life span.

In order to further clarify the central notions of emotional engagement and social interaction as part of a second-person approach to other minds and to illustrate that this view has already begun 
to prove productive in shaping research outside the neurosciences, in what follows, we will draw on and review evidence from the fields of developmental, social and cognitive psychology.

\subsubsection{Developing awareness of minds through second-person engagements: Evidence from} developmental psychology

Debates in developmental psychology concerned with the processes through which infants and young children come to recognize the existence and nature of other minds reflect the same assumptions that have beset the traditional philosophical debates. They have most often posited two sources of information for the developing child - that of first-person experience and thirdperson observation - or on occasion an unconvincing amalgam of the two. The possibility of a difference in awareness in different relations with specific 'other minds' - which is the central assumption of a second-person approach to mind knowledge (Reddy 2003, 2008) - was either neglected or explicitly denied (Barresi \& Moore 1996). There has, however, been a dramatic surge of interest in second-person explanations within development (e.g. Carpendale \& Lewis 2004; Gallagher 2001; Hobson 1991, 1999; Reddy 1996, 2003, 2008).

Evidence for the second-person argument, namely that an appropriate development of awareness of other minds depends on the infant first experiencing minds which are directed towards her, is scattered throughout the developmental psychological literature. Probably the most impressive evidence of infants' sensitivity to and preference for the infant-directedness of interpersonal actions comes from recent studies concerning early responses to gaze. Mutual gaze both reflects one organism's interest in another's gaze and signals this interest to the other, with the potential for creating a situation of intense mutuality. Between two and five days of birth, human neonates show a preference for looking at faces or pictures of faces with eyes directly looking towards the infant. This preference reveals itself both in terms of longer looking times and in terms of more frequent looks (Farroni et al. 2002). Even earlier than this, within minutes of birth, infants show considerable interest in and respond appropriately to self-directed facial actions, primarily more noticeable actions such as tongue protrusion and opening the mouth wide (Kugiumutzakis 1998; Meltzoff \& Moore 1977; Nagy \& Molnar 2004). Also, there is evidence that by four months of age the experimenter's gaze directed toward rather than away from the infant leads to a variety of neural reactions and information processing advantages: higher cortical arousal (Farroni et al. 
2002), enhanced occipital early gamma response (Grossman et al. 2007), enhanced neural processing of emotional expressions (Striano et al. 2006), facilitated neural processing of objects (Reid et al. 2004), and differential processing of words (Parise et al. 2008). By two months of age infants already show a variety of emotional reactions to attention directed to the self, ranging from pleasure (Wolff 1987) to distress if unable to disengage (Brazelton 1986) to ambivalence in the form of coy smiles (Reddy 2000). A large number of studies have shown that the intricacies of emotional engagement matter from very early infancy and are the source of meaning about self and others. Two- to three-month-olds during face-to-face communication demonstrate intra- and interpersonal coordination (Fogel 1993; Lavelli \& Fogel 2002; Stern 1985; Trevarthen 1977), are disturbed by the lack of temporal and affective coordination (Cohn \& Tronick 1989; Legerstee \& Varghese 2001; Murray \& Trevarthen 1985; Nadel \& Tremblay-Leveay 1999), are affected in their ability to bid for attention by the history of maternal affective responses (McQuaid et al. 2009) and learn to prefer the levels of interactional contingency they are familiar with (Bigelow \& Rochat 2006).

Infant awareness of attention in second-person engagements has been argued to have developmental primacy over the awareness of attention in triadic and more temporally extended attentional engagements (Reddy 2003, 2005, 2008). Evidence for the causal role of such engagements in developing triadic and more complex reflective awareness comes from developmental psychopathology (particularly autism) where problems with explicit social cognition (at the level of triadic joint attention or at the level of concepts of self or of other) are heralded by problems in second-person engagements (with establishing mutual attention and mutual responsiveness with self and with other; Leekam \& Ramsden 2006; Reddy et al. 2010; Reddy, in press).

The primacy of second-person engagements creates serious conceptual and methodological problems for psychological research: it demands that emotion be taken as central to an awareness of minds and focuses on emotional responses rather than reflections or constructs. We argue that such experiences of mind and mentality are first and most intensely experienced within secondperson engagements, where the individual is directly addressed by and responds to an 'other' 
mind. Such second-person experiences of other minds, we argue, are necessary for the typical development of social understanding and continue to influence social understanding throughout life.

\subsubsection{Knowing Minds in Interaction: Evidence from social and cognitive psychology}

In social psychology and related fields - in spite of a long history and interest in "social presence" effects (e.g. Allport 1924; Biocca et al. 2003; Short et al. 1976; Triplett 1898; Worringham \& Messick 1983; Zajonc 1965) - the need to allow test subjects to leave the "experimental quarantine" of "isolation paradigms" when studying social processes has only recently been recognized (e.g. Becchio et al. 2010; Richardson et al. 2007; Sebanz et al. 2006). This development appears to be based on the assumption that cognition is grounded in basic perception and action processes and emerges out of the interaction of the organism with its environment and that - rather than treating it as an experimental confound - a social context and social interaction can be treated as an independent variable of experimentation. Consistent with this proposal, the second-person approach sees interaction with other agents and the ensuing interaction dynamics as crucial for the knowing of other minds and the expression of that knowledge.

The role of social interaction for cognitive and social development has begun to gain centre stage in various scientific discourses (De Jaegher et al. 2010): The role of interaction as a vehicle for the acquisition of knowledge has for instance been demonstrated in language development. In contrast to the Chomskian idea of a "Language Acquisition Device" (e.g. Chomsky 1979), the perception of structure in social interactions has been shown to guide vocal development and language learning (Bruner 1983; Goldstein \& Schwade 2010), both in terms of speech perception (Kuhl 2007a,b; Kuhl et al. 2003) or turn-taking (Goldstein \& Schwade 2008; Goldstein et al. 2009; Jaffe et al. 2001). Whereas children can extract statistical regularities from any structured material without awareness or intention using mere error feedback (Marcus et al. 1999; Saffran et al. 1997), observation of one's own behavioral outcomes in interaction may be crucial for such learning to occur (Goldstein et al. 2010). Adults also coordinate turn-taking, implicitly agree upon names for objects (Brennan \& Clark 1996; Brennan \& Hanna 2009), approach each other's accents (Giles et al. 1992), sway their body in synchrony (Shockley et al. 2003), and visually 
coordinate their attention through synchronized eye movements (Richardson et al. 2007) suggesting that communication may be grounded by a shared context, which is actively developed in ongoing encounters (Clark 1996; Garrod \& Pickering 2004).

In other areas of research "interaction" has been investigated by focusing on processes such as involuntary mimicry (e.g. Chartrand \& Bargh 1999; Konvalinka et al. 2010; Niedenthal et al. 2010; Schmidt et al. 1990), which leads to enhanced rapport and liking, but is also influenced by differences in affiliative motives and interdependent self-construal (Van Baaren et al. 2003, 2004). Social interaction, however, normally also involves more complex forms of coordination present from early on in life (cf. Harrist \& Waugh 2002). In this respect, Knoblich \& Sebanz (2008) distinguish between "action simulation" (see also Rizzolatti \& Sinigaglia 2010), "joint attention" and "shared intentionality" (see also Tomasello \& Carpenter 2007). The development of a shared perceptual and attentional space within early mutual attentional engagements is crucial, since it paves the way for triadic interactions, in which we share our mental states about a third object or person with the other (Tomasello 1995). In turn, such triadic attentional engagements may be crucial for developing complex joint actions (Fiebich \& Gallagher, in press; Knoblich \& Sebanz 2008; Richardson et al. 2007; Sebanz et al. 2006).

In spite of a growing interest in this matter, the bulk of research is still rooted in a mechanistic metaphor of feedback loops that inform individuals about the adequacy of their behavior. In this framework, it is assumed that the sum of two interacting agents can be expressed in terms of processes 'within' those agents (however, modified by the external world, in this case each other). We argue that interaction expresses a type of knowledge of other minds that is not entirely reducible to knowledge 'inside' any two individual agents but exists "between" them (see De Jaegher et al. 2010). Interestingly, the recently developed "perceptual crossing paradigm" directly addresses this aspect (Auvray et al. 2009; Lenay et al. 2011): here, two participants interact with each other by moving their mouse cursor in a one-dimensional virtual space. In this space they can encounter three different types of objects indicated by tactile stimulation: a fixed object, a constantly moving object, and the other participant. Their task is to click the mouse only if they believe to have encountered the other person's cursor. Thus, it is only when they meet each other, that both are stimulated simultaneously. Using this setup, it was shown that healthy volunteers exhibit a dissociation between task performance and awareness of this performance with respect 
to the detection of reciprocity (though not with respect to the detection of animacy): conscious identification of the other person (by means of clicks) is limited to distinguishing both moving objects from the fixed object (animacy detection), but does not extend to distinguishing the moving object from the other person's object (reciprocity detection). However, participants' interaction dynamics allow us to distinguish not only between fixed and moving objects, but also between the moving object and the other's cursor (Auvray et al. 2009). Crucially, this demonstrates that unrelated to awareness and strategic processes, people are sensitive to reciprocal interaction, and furthermore spontaneously engage in mutual modification of action patterns with an interactor, actively "seeking the other out". It is only in this interactive process that contingencies are simultaneously experienced and acted upon.

Taken together, recent progress in developmental, social and cognitive psychology indicates a surge of interest in emotional engagement and real-time social interaction as key constituents for knowing other minds. While, in fact, this second-person approach has already begun to prove productive in shaping experimental work, this has occurred largely outside the realm of neuroscience. We suggest that the approach promises to do the same within the field of social neuroscience, thereby leading to the establishment of a second-person neuroscience. 


\section{Toward a second-person neuroscience}

After more than a decade of successful research, 'dark matter' remains in the field of social neuroscience (Figure 2). As highlighted above previous research has often focused on the perception of inert stimuli - consistent with the idea of a detached observer- whereas, in everyday life, making sense of others requires both emotional engagement and interaction (Figure 1). Consequently, a second-person neuroscience will help to address differences in the neurobiological underpinnings of social knowing related to

i) a person being a detached observer as compared to experiencing a social situation with an attitude of emotional engagement (Figure 2: 'experience')

ii) experimental paradigms used to investigate social cognition allowing or not allowing for interaction (Figure 2: 'participation') ${ }^{2}$

iii) data collection and analysis taking place at the level of a single or two (or more) individuals (Figure 2: 'data collection \& analysis') ${ }^{3}$.

In the following we will review evidence from neuroimaging and psychophysiology to demonstrate the relevance and applicability of the first and second dimension of our conception of a second-person grasp of other minds (section 3.1). Additionally, we will discuss some of the methodological challenges associated with addressing the third dimension and other important milestones in the development of a second-person neuroscience (section 3.2).

\footnotetext{
2 Here, it is important to note that from a conceptual point of view we do not see the differences between the dimensions of 'experience' and 'participation', as being strictly categorical in nature. Also, it is important to emphasize that we are, here, referring to the characteristics of experimental paradigms, which do (or do not) elicit a sense of emotional engagement and which allow (or do not allow) a human subject to participate in social interaction.

3 From our perspective, making experimental paradigms more interactive and ecologically valid will allow assessing differences in the neural correlates of social cognition from an observer's as compared to from an interactor's point of view in an individual's brain (see Figure 1). In addition to that, however, another important question will be to investigate whether more insights can be gleaned from quantifying inter-brain effects of social interactions and to assess whether two interacting brains provide more information about the interaction than the sum of the individual brains (e.g. Hasson et al. 2012; see also Section 3.2.2).
} 


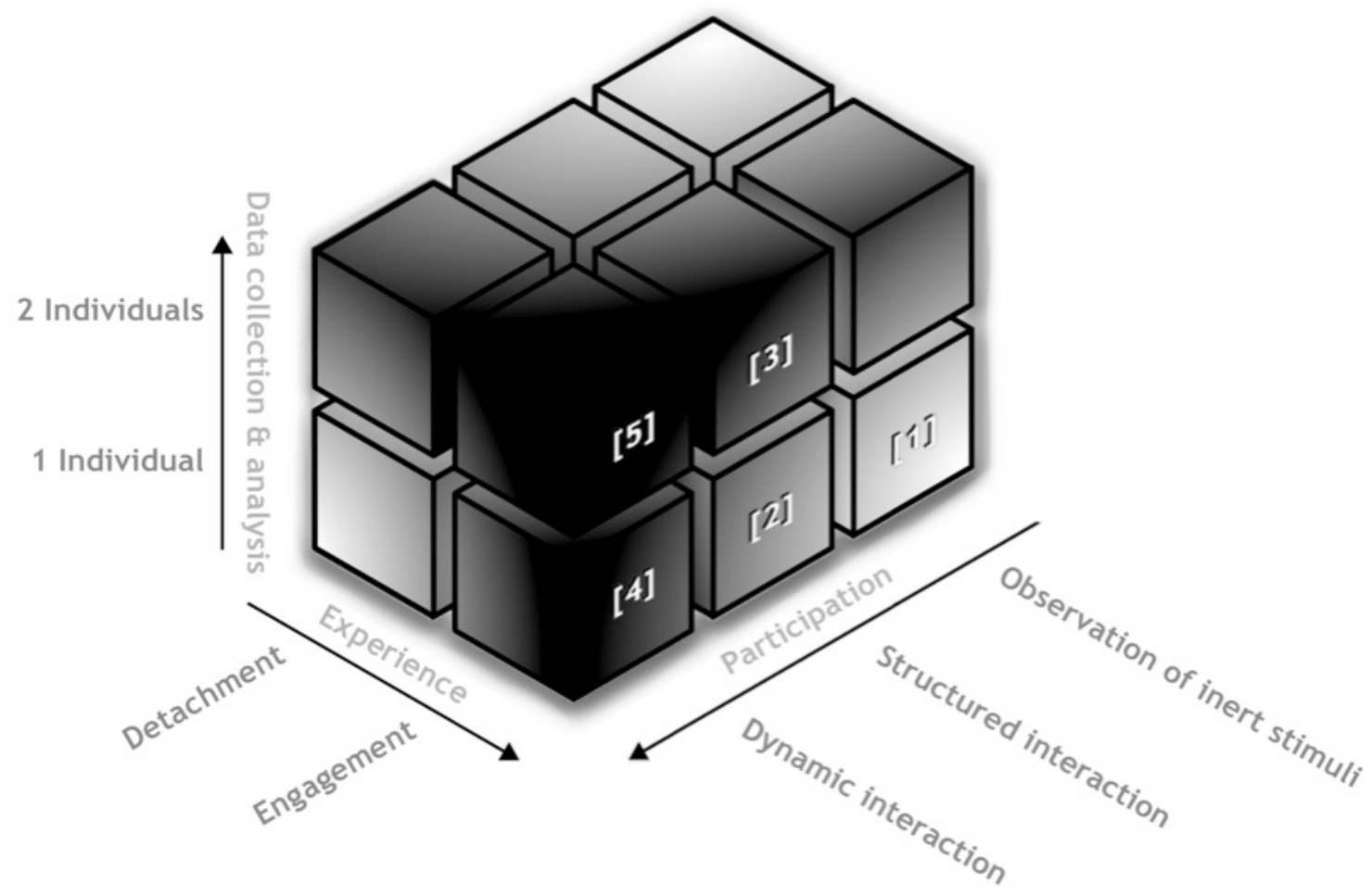

Figure 2. Depiction of the experimental 'landscape' of a second-person neuroscience.

Cubes shown in this figure represent categories of experimental approaches to the investigation of social cognition in accordance with the second-person account. Here, we highlight cubes 1-5, which in accordance with the text are most informative as to the different aspects of the research landscape: Cube [1], e.g. represents studies, which target differences between detached observation as compared to emotional engagement (see section 3.1.1). Cube [2] represents studies which use paradigms that allow the participant to directly influence the stimulus material, i.e. seeing the effect of her actions (e.g. interactive eyetracking studies; see section 3.1.2). Cube [3] represents studies that collect data from two participants who interact by means of a structured task, including hyperscanning studies that e.g. make use of game theory paradigms (see section 3.2.1). Cubes [4] and [5] represent studies which allow for the investigation of ecologically valid, real-time interactions (see 3.2.2). More intense shades of grey indicate areas of the landscape, which have been left largely unexplored, representing the 'dark matter' of social neuroscience. 


\subsection{Preliminary evidence from functional neuroimaging and psychophysiology}

\subsubsection{Being Addressed as You: The neurobiological correlates of emotional engagement}

Based on the hypothesis of differences in the neural processing of social stimuli depending upon whether or not they are directed toward oneself as compared to being directed toward someone else, we performed a functional magnetic resonance imaging (fMRI) study (Schilbach et al. 2006), in which participants were asked to imagine being part of a scenario with three others, only one of which being visible (Figure 3A), and were shown short video sequences depicting this virtual character, which exhibited socially relevant facial expressions or arbitrary facial movements. Furthermore, it was varied whether or not the virtual character looked directly at the participant (Figure 3B) or towards the right or left in the direction of an invisible agent (Figure 3C). Participants were asked to rate in all cases whether they felt that the virtual character had expressed an intention to initiate a social interaction. 


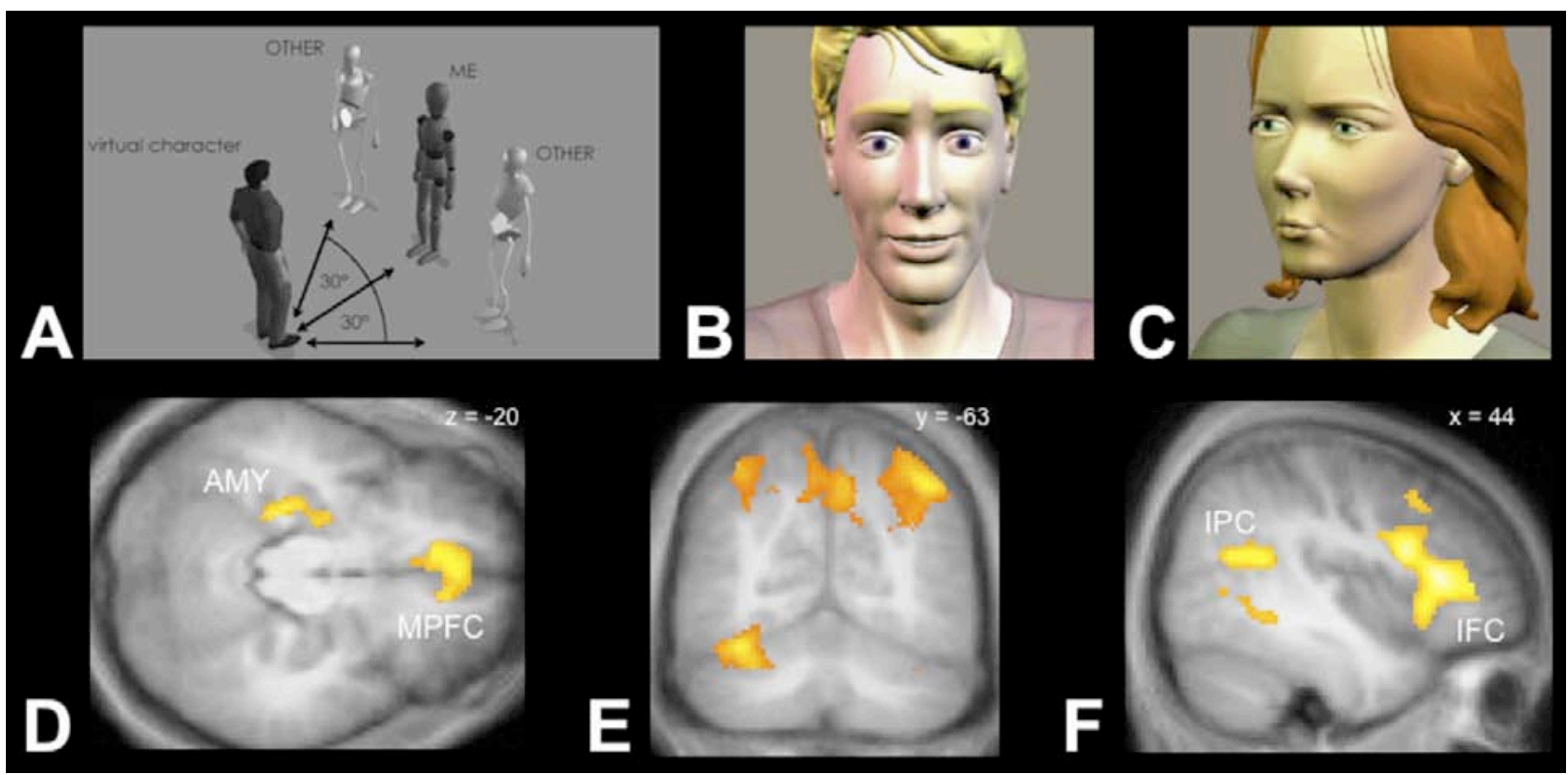

Figure 3. A) Virtual scenario as shown in the instructions. B) Self-directed, socially relevant facial expression. C) Other-directed, arbitrary facial movement. D) Neural correlates of the perception of selfdirected facial expressions. E) Neural correlates of the perception of other-directed facial expressions. F) Neural correlates of the perception of arbitrary facial movements. Activation overlays based on reanalysis of data taken from: Schilbach et al. (2006). 
The behavioral results demonstrated that participants did not have difficulties in differentiating socially relevant from arbitrary mimic behavior. Interestingly and in spite of the explicit instruction to "put themselves into the shoes of the other", participants demonstrated a bias towards giving socially relevant facial expressions a significantly higher rating when they were self-directed. In parallel to this, results of the neuroimaging analysis demonstrated significant differences in activation patterns subserving the perception of socially relevant facial expressions depending upon whether these expressions were self- or other-directed: while self-directed facial expressions led to a differential increase of neural activity in the ventral portion of MPFC and the (superficial) AMY (Figure 3D), other-directed facial expressions resulted in a differential recruitment of medial and lateral parietal cortex (Figure 3E). Our findings, therefore, demonstrate that while the perception of socially relevant nonverbal cues from an observer's point of view recruits brain regions that have been related to visuo-spatial processing, the perception of identical, self-directed stimuli activate brain regions that have been related to emotional and evaluative processing (Schilbach et al. 2006).

Indeed, the AMY is known to be a crucial subcortical hub of the limbic system serving various integrative sensory and emotional functions in attaching biological and social significance to stimuli (Gamer \& Buchel 2009; Gamer et al. 2010; Muscatell et al. 2010; N'Diaye et al. 2009; Tamietto \& de Gelder 2010). The ventral portion of MPFC is also known to be relevant for emotional processing and has been implicated to be involved in "outcome monitoring" (Amodio \& Frith 2006). More generally, emotions are known to be an important driving force for interpersonal behavior and a 'short hand' that guides decision-making processes (e.g. Frijda 1986; Damasio 2010). Also, emotions are assumed to be of crucial importance for interpersonal perception by allowing the observer to share the feeling state of another individual (Preston \& de Waal 2002). Apart from this traditional view of how emotions might contribute to social cognition, our account views emotional responses not only as a way of perceiving emotional states in others, but also as a way of being engaged with others, which could contribute to the understanding of the bodily intentionality of the other in terms of bodily responsiveness (Rietveld 2008). Being responsive to the socially relevant, expressive behavior of others in this way could provide and bias possibilities for (inter-) action by motivating behavior and soliciting activity. 
Interestingly, our neuroimaging analysis also demonstrated that the perception of arbitrary facial movements recruited the right inferior frontal and inferior parietal cortices (Figure $1 \& 3 \mathrm{~F}$ ). These brain regions are commonly described as important nodes of the MNS, which has been related to understanding the (motor) intentions that underlie others' actions (Rizzolatti \& Sinigaglia 2010). This finding, we think, is interesting in several respects: first of all, it suggests that activity in the MNS is not related to the particular perspective a human observer adopts, but more closely tracks the observed behavior itself regardless of whether it is 'my action' or 'your action'. This seems to be consistent with the dominant interpretation of MNS activity in the literature suggesting that the MNS may have evolved to represent actions in the same way across subjects and that mirror neurons explain the ability to understand other minds by giving us a "first-person grasp" of the motor goals and intentions of other individuals (Rizzolatti \& Sinigaglia 2010). This view has, however, been criticized as over-emphasizing similarities in self- and other-related processes (Schilbach 2010) and under-representing the important question of where mirror neurons actually 'come from' (Heyes 2010). Here, an important suggestion has been that mirror neurons may only play a role in situations when the action and its stereotypic context are highly familiar (e.g. Brass et al. 2007). In our study, however, brain regions described as corresponding to the MNS, respond more strongly to arbitrary facial movements than to socially relevant ones, which appears to contradict the idea that the MNS only plays a role in familiar situations. On the contrary, an arbitrary facial movement - with which one may be less familiar than with socially relevant facial expressions, which are directed towards another person more frequently - also leads to the recruitment of the MNS. This finding could be understood in terms of a prediction error signal (Pelphrey et al. 2003; Schippers \& Keysers 2011) and could be relevant to associative learning processes recently discussed as an alternative account of the development and modulation of activity in the MNS (Heyes 2010).

In fact, according to the "associative hypothesis" (Heyes 2010), mirror neurons are forged through sensorimotor experience of observing and executing actions and the MNS, even in adulthood, can be reconfigured through sensorimotor learning. Evidence for this comes from a series of elegant studies, which demonstrate that sensorimotor experience can enhance (Press et al. 2007), abolish (Heyes et al. 2005) and even reverse (Catmur et al. 2007, 2008) 'mirror' activation in human participants. Consistently, a recent simulation study demonstrated that a reinforcement learning based model could account for the development of mirror neurons in gaze 
following (Triesch et al. 2007). With respect to the possible sources of sensorimotor experience that may impact on the MNS, Heyes (2010) has recently emphasized that much of this experience is obtained through interaction with others. We strongly support this position and argue that the investigation of action observation and execution in a more ecologically valid, interpersonal context — as suggested by a second-person neuroscience — will help to investigate these matters further (cf. Kourtis et al. 2010). More specifically, we see a role for the MNS beyond mere motor resonance: rather than suggesting that mirror neuron activity constitutes a simulation routine which gives us a "first-person grasp" of the other (Rizzolatti \& Sinigaglia 2010), we contend that an understanding of the MNS on the enactive view of cognition would suggest that activity in these regions might be more closely related to the ability to perceive social affordances, i.e. the possibilities for interaction provided by others, in terms of an activation of motor programs that could allow for interpersonal coordination of behavior (cf. Gangopadhyay \& Schilbach, in press). This view is consistent with the idea of social interactions having a profound impact on MNS activity and offers a more plausible account for actions that people perform jointly as these often involve complementary or incongruent actions rather than imitative or congruent ones (cf. Fuchs \& De Jaegher 2009; Gallagher 2007). Indeed, a recent study by Newman-Norlund and colleagues (2007) found evidence that the MNS is more active during the preparation of complementary actions while other studies demonstrate that activity in the human MNS can be modulated by social interaction (Kourtis et al. 2010; Oberman et al. 2007). This is clearly in line with our suggestion that an essential aspect of apprehending other minds lies in the kinds of responses their activity elicits (see Figure 1).

In a follow-up experiment to our fMRI study, the paradigm was used while recording eyemovements, pupil size and facial electromyography (EMG). The results show that attention allocation, as assessed by fixation duration, was specifically related to the perception of selfdirected stimuli. EMG measurements demonstrated that facial activity was influenced by the perception of socially relevant facial expressions, demonstrating spontaneous, involuntary facial responses that have been described as "facial mimicry" (Mojzisch et al. 2006). While we did not observe a statistically significant interaction effect here, the difference in EMG activity between self- and other-directed facial expressions was noteworthy (see Schilbach et al. 2008a, for details). Using the temporal information from the EMG study, we re-analyzed the fMRI data to investigate the neural correlates of facial mimicry. This analysis identified a network comprising 
the face region of the primary motor cortex, but also the posterior cingulate cortex, hippocampus and the dorsal midbrain. This is suggestive of a close link between the perception of facial expressions and their generation in the observer. Facial expressions might be particularly prone to engaging such mechanisms as they serve important communicative functions. Furthermore these findings demonstrate that situations which lead to emotional engagement and invite an element of a motor response, recruit both fronto-parietal areas as well as the cortical midline structures and differentially activate the limbic system of the brain (Schilbach et al. 2008a; cf. Buck et al. 1992; see Figure 1).

Taken together, the results of these studies demonstrate significant differences in the neurobiological mechanisms of the perception of facial expressions depending upon emotional engagement. When we are personally addressed by others, the perception of their mimic behavior relis, in neurobiological terms, upon tight perception-action coupling with affective and bodybased processing feeding into and promoting the preparation of motor responses as a way of picking up and responding to the possibilities for interaction.

\subsubsection{Minds made for sharing: The neurobiological correlates of the reciprocity of social interaction}

As outlined above, interaction loops must be considered as important constituents of secondperson relations. Thus, within social interaction, interactors mutually and directly influence each other and may hold different roles during the interaction (as introduced in section 2.1; see Figure $1 \mathrm{C} \& \mathrm{D})$. To establish a paradigm that allows participants to be part of a social interaction in the constrained fMRI setting, we have developed a novel technique that makes use of eyetracking data obtained from participants inside the scanner to control a virtual character's gaze behavior in real-time making it 'responsive' to the human observer's gaze (Wilms et al. 2010). This setup, therefore, allows participants to experience their own eye-movements to have an effect on the gaze behavior of a (virtual) other similar to how this occurs in real-life situations. Importantly, such a setup can allow the investigation of cognitive phenomena which are at the interface of automatic and controlled processes, as eye-movements are known to be closely related to both (e.g. Hikosaka \& Isoda 2010). Also, the setup allows us to investigate phenomena whose 
emergence necessarily depends upon social interaction, its reciprocity and whose underlying psychological processes and neural mechanisms may differ depending upon the roles interactors hold during interaction, namely those of being 'initiator' or 'responder' in the interaction.

With respect to the phenomenon of joint attention, i.e. attending to something together with someone and being aware that 'we both' are attending, the latter appears to be highly relevant: joint attention can occur either as a result of following someone else's gaze toward an object ('responder') or as a result of directing someone else's gaze toward the object ('initiator'). Clinically, children with autism, in fact, show less pronounced impairments in their ability to respond to a person's gaze shifts (by following the gaze) than in their spontaneous drive to initiate the sharing of attention (by trying to make someone look at something; Mundy \& Newell 2007).

Based on the hypothesis that differences in the neural basis of joint attention could be related to the reciprocity of social interaction (as compared to previous social neuroscience attempts to investigate the neural correlates of joint attention by means of tasks in which participants are mere observers of gaze cues (e.g. Williams et al. 2005; Materna et al. 2008; see also section 2.1), the setup described above was used to perform an fMRI study, in which participants interacted with the virtual other while undergoing neuroimaging (Schilbach et al. 2010a). Experimental variations consisted of initiating vs. following the gaze of the virtual character when fixating objects shown on the stimulus screen (Figure 4A). Our results demonstrate the recruitment of MPFC and PCC for joint attention to an object, regardless of whether or not this was initiated by the participant or the (virtual) other (Figure 4B). Conversely, looking at an object different from the one inspected by the virtual other led to the recruitment of a lateralized fronto-parietal network (Figure 4C). While the latter closely resembles the neural network which has been related to the control of attention and eye-movements (Corbetta et al. 2008; Pierrot-Deseilligny et al. 2004), the former regions closely match those which have been described as belonging to the MENT (Frith \& Frith 2006; Kampe et al. 2003) while overlapping with others that have become known as the "default mode of brain function" (Raichle et al. 2001; Schilbach et al. 2008b; Schilbach et al. in press). 


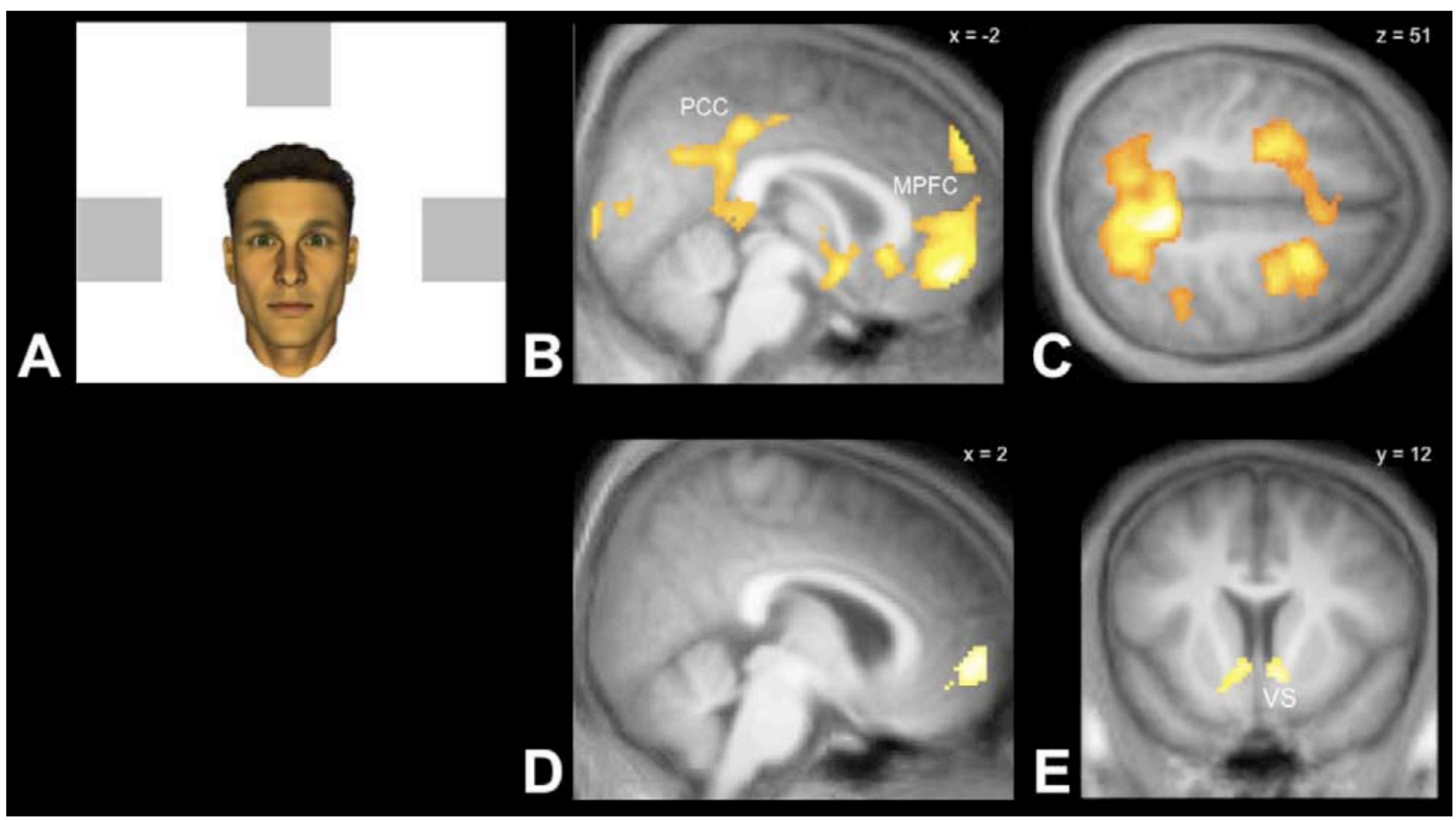

Figure 4. A) Screenshot depicting an anthropomorphic virtual character and three objects (grey squares). B) Neural correlates of main effect of joint attention. C) Neural correlates of non-joint attention. D) Neural correlates of other-initiated joint attention. E) Neural correlates of self-initiated joint attention. Activation overlays based on a reanalysis of data taken from: Schilbach et al. (2010a). 
In spite of participants always fixating an object on the stimulus screen, the underlying brain activity appears to be markedly different depending upon whether or not the participant is doing this 'together' with a virtual other or not. Doing so in coordination with the virtual character resulted in a differential increase of neural activity in a network whose activity has been related to the human ability for grasping another person's mental states, her communicative intentions and for using an internally oriented mode of cognizing to contextualize aspects of a situation (Amodio \& Frith 2006; Bar 2007; Buckner \& Carroll 2006; Kampe et al. 2003; Schilbach et al. 2008b). Here, it is important to stress that the MENT was activated as a result of participants simply and naturally coordinating their gaze with that of the other without any explicit instruction to assess the mental states of the virtual other. This is consistent with the observation of activations of dorsal MPFC when study participants were addressed by their first names or by faces looking directly at them (Kampe et al. 2003). Our findings, therefore, seem to contradict the proposal that the mentalizing network is responsible for reflective and more explicit social cognition (Keysers \& Gazzola 2007). In essence, we are able to show that this network is activated as a result of interpersonal coordination in social interaction, which was also experienced as more pleasant and less effortful than doing the opposite of what the virtual character was doing (cf. Schnell et al. 2011). Follow-up studies using modifications of our novel paradigm will investigate putative connectivity differences between areas of the MENT during social interaction and observation and will explore how a cooperative or competitive context influences the neural mechanisms of a gaze-based interaction (Figure 1; see sections 3.2 and 5 for further details).

Our findings, therefore, raise the intriguing possibility that activity changes in the MENT can occur as a result of (gaze-based) social interaction (cf. Allen \& Williams 2011). To us it is tempting to think of this finding as paralleling the suggestions of Heyes (2010) with respect to the MNS, giving rise to the hypothesis that similar associative mechanisms might play a role in the case of the MENT. In a similar line of thought, Behrens and colleagues have demonstrated that social prediction error signals — when learning from the behavior of or advice provided by others - are coded by MENT components, which they describe as evidence for the argument that higher-order social cognitive mechanisms may rely on simple associative processes (Behrens, Hunt \& Rushworth 2009). Crucially, the elegant computational approach taken by Behrens and 
colleagues to investigate reward-based learning and decision-making uses a generative model, allowing the consideration of the learning history to predict changes in neural activity over time. Similarly, we suggest, future research in social neuroscience should investigate the development and changes in neural networks, i.e. the neural plasticity related to and induced by real-time social interactions, thereby helping to understand how particular functions actually develop in particular areas of the brain or brains of interactors (cf. Westermann et al. 2007; see Figure 1 and section 5 for more details).

Furthermore, our neuroimaging finding of a differential increase of neural activity in the MENT is particularly relevant, because it is observed during joint attention: Ontogenetically, joint attention is known to be a most important precursor of explicit social cognitive abilities and predates these conceptual abilities by years: A recent study was, indeed, able to show that children have an implicit 'know how' of what others experience long before passing false-belief tasks, when they encounter them in joint engagement (Moll et al. 2007). Based on our findings, it can be assumed that joint attention in social interaction already relies upon the brain regions of the MENT before children pass tasks that require an explicit knowledge of others' mental states (cf. Grossmann \& Johnson 2010). Rather than being a network that is exclusively devoted to reflective social cognition, this network might, therefore, be trained up by participation in social interaction in terms of basic mechanisms which allow the use of analogies and associations to generate predictions (Friston 2008; Mitchell 2009). During later stages in development this network may then be brought into the service of explicit social cognition (Frith \& Frith 2008), which - at the level of the brain - could be reflected in differences in the functional or effective connectivity between individual brain regions, rather than functionally segregated effects (e.g. Sporns et al. 2004; Daunizeau et al. 2010a,b). In these terms, the progression from perceiving and being motivated to respond to relevant social stimuli to understanding them may be a result of the matching of top-down and bottom-up expectations. Importantly, bi-directional relationships between different levels of neural processing may remain relevant throughout life (Teufel et al. 2010; see Figure 1).

Returning to the results of the fMRI study on joint attention, it is of crucial importance that differences in the neural correlates were also observed depending upon joint attention being selfor other-initiated: while following someone else's gaze to engage in joint attention resulted in the 
recruitment of the anterior portion of MPFC (aMPFC; Figure 4D) known to be involved in the enhancement of stimulus-oriented attending (Burgess et al. 2007), directing someone else's gaze towards an object activated the ventral striatum (VS), part of the functional neuroanatomy of reward processing (Figure 4E). In light of ratings of subjective experience also obtained from participants during a post-scan questionnaire — which indicated that they enjoyed looking at objects more 'together with' the virtual other - the latter finding, indeed, appeared to be related to the hedonic aspects of experiencing self-initiated joint attention (Schilbach et al. 2010a). This seems to be in line with the idea that social interaction may involve collaborative and affiliative motives, the realization of which is experienced as rewarding, possibly relying upon an 'intrinsic' motivation of humans for sharing of experiences (Tomasello 2009; Trevarthen 1980). Furthermore, these findings demonstrate how basic motivation- or reward-related signals may play a key role in the establishment and maintenance of social relations (e.g. Panksepp et al. 1980), which appears to be a crucial area for future research in social neuroscience (see section 5.2 for further details). Most importantly, our results provide clear evidence that the neural circuitry used during social interaction differs from the circuitry recruited during 'individual' social cognition when one's behavior does not have effects on the 'object' of one's cognition (cf. Schilbach et al. 2010a; Williams et al. 2005; Materna et al. 2008).

\subsection{Methods for a Second-Person Neuroscience}

Advancing research in social neuroscience as suggested by a second-person approach requires both upon a refinement of conceptual issues, the derivation of concrete hypotheses as well as the development of adequate methods to address these questions. It is to the discussion of the latter that we turn in the following section. Concrete ideas for experiments based upon our conception of the constituents of a second-person approach as outlined in section 2 are discussed in detail in section 4.

\subsubsection{Top-down and bottom-up investigations of social interaction}

In the joint attention paradigm, participants interact with anthropomorphic virtual characters, who they believe are controlled by other human participants (Wilms et al. 2010). In this paradigm, we are in a position to investigate the behavioral and neural correlates of interaction contingencies and responses that are characteristic of various forms of social encounters (Figure $1 \& 2$ ). Future 
studies will make use of this setup to explore the interaction of explicit and implicit processes in social cognition and how this may depend upon being able to 'get into the action'. Here, one could specifically ask whether the difference between social cognition from an interactor's as compared to an observer's point of view merely adds an action component or whether this actually changes other psychological processes. In terms of the underlying neural substrates such differences might be characterizable in terms of overlapping versus distinct neurocircuits or could be related to differences in connectivity between 'social brain' regions (Figure 1). Also, the question could be addressed whether ostensive cues exchanged between interactors (e.g. mutual gaze; Csibra \& Gergely 2009) are equally effective from an observer's point of view as compared to situations when one is personally addressed.

Furthermore, paradigms are being developed in our laboratory, which will help to understand differences between social cognition from an interactor's as compared to an observer's point of view with respect to reward-based interactions (cf. Pessoa \& Engelmann 2010). Based on the assumption that social interaction per se may be experienced as motivating and rewarding, it appears plausible to devise paradigms that implement a social context, in which task performance may be modulated depending upon whether or not the motivation to interact socially is parallelized with or contrasted with performing the task (see section 5.1.1 for further details). Another extension of the above described joint attention paradigm could consist in using virtual characters whose facial expressions and whole-body movements could also be manipulated. This setup would allow the investigation of how participant-directed gaze behavior of the virtual character would influence the perception of, for instance, reaching or grasping movements in peri- and extrapersonal space (cf. Caggiano et al. 2009). Here, an interesting possibility would be to parametrically vary the degree to which a virtual character is responsive to a human observer's gaze in real time to investigate how this may lead to differential recruitment of the MNS and MENT of the brain (Brass et al. 2007; de Lange et al. 2008; Wheatley, Milleville \& Martin 2007; Santos et al. 2010). Also, the presentation of real-world objects that can be attended to both by the virtual character and the participant could be helpful to manipulate neural activity in those large-scale neural networks.

Another fundamental question for a second-person neuroscience - closely related to the 'problem' of other minds - consists in asking which factors actually determine that we perceive 
an interaction as an exchange with a mindful rather than a machine-driven agent? To this end, a "nonverbal Turing test" can be devised, in which participants engage in gaze-based interaction with an anthropomorphic virtual character, whose gaze behavior is either controlled by another participant or by a computer (Figure 2; Pfeiffer et al., in press). These investigations are likely to be informative with respect to the impact of valence (whether or not an interaction subjectively feels positive or rewarding) as compared to contingency (the degree to which the virtual character objectively follows or does not follow one's gaze). Furthermore one can address the question of the congruency of the behavior shown by the virtual character during the interaction, i.e. whether following or not following the participant's gaze has an impact on ratings of sympathy and trustworthiness as well as subsequently evoked prosocial behavior shown towards the person one has interacted with.

\subsubsection{From interaction loops to interaction dynamics}

In the early years of social neuroscience attempts had already been made to investigate two brains in interaction through "hyperscanning", hailed as a break-through technology, (Montague et al. 2002). While the application of this method has, indeed, provided invaluable insights into the neural basis of social cognition in conditions of health and pathology (e.g. King-Casas et al. $2005,2008)$, the approach never really caught on. At least in part this is due to the fact that using it to its full potential would have required establishing more ecologically valid ways for two or more participants to interact (cf. Redcay et al. 2010). Most hyperscanning studies, however, have relied upon experimental paradigms from game theory, which allow for a highly structured, titfor-tat kind of interaction. The latter can be elegantly formalized mathematically, but can also be criticized for not recreating the interaction dynamics of everyday-life social encounters. Also, paradigms from game theory are deeply entrenched in a cognitivist view of the subject as a (rather) rational and (rather) passive recipient of information, which may not fully capture many aspects of naturalistic social interaction, including the ways in which interactors co-regulate their behavior (cf. Bacharach 2006; Hertwig \& Erev 2009; Schonberg, Fox \& Poldrack 2011).

However, first steps are now being taken to realize the investigation of the neural mechanisms of interaction dynamics (Figure 2: cubes [4] \& [5]). Similar to our approach of using gaze behavior to allow for direct social interaction (Schilbach et al. 2010a; Wilms et al. 2010), the recent work 
of Saito and colleagues (2010) capitalizes on the idea that inter-subject synchronization at the neural level might occur during eye contact. Using a similarly minimalist and yet naturalistic setup allows the experimental control of bandwidth, i.e. the degree of complexity of the interaction, which may be helpful in focusing on its temporal dynamics (cf. Auvray et al. 2009). For their ground-breaking study Saito et al. have devised a setup in which they not only use hyper-scanning, but also allow participants to interact in real-time by exchanging gaze behavior. To this end two MRI scanners were equipped with infrared eyetracking systems and video cameras. Thereby a live video image of the respective interaction partner's face could be broadcast into the respective other scanner to generate a mediated face-to-face situation (Figure $5)$.

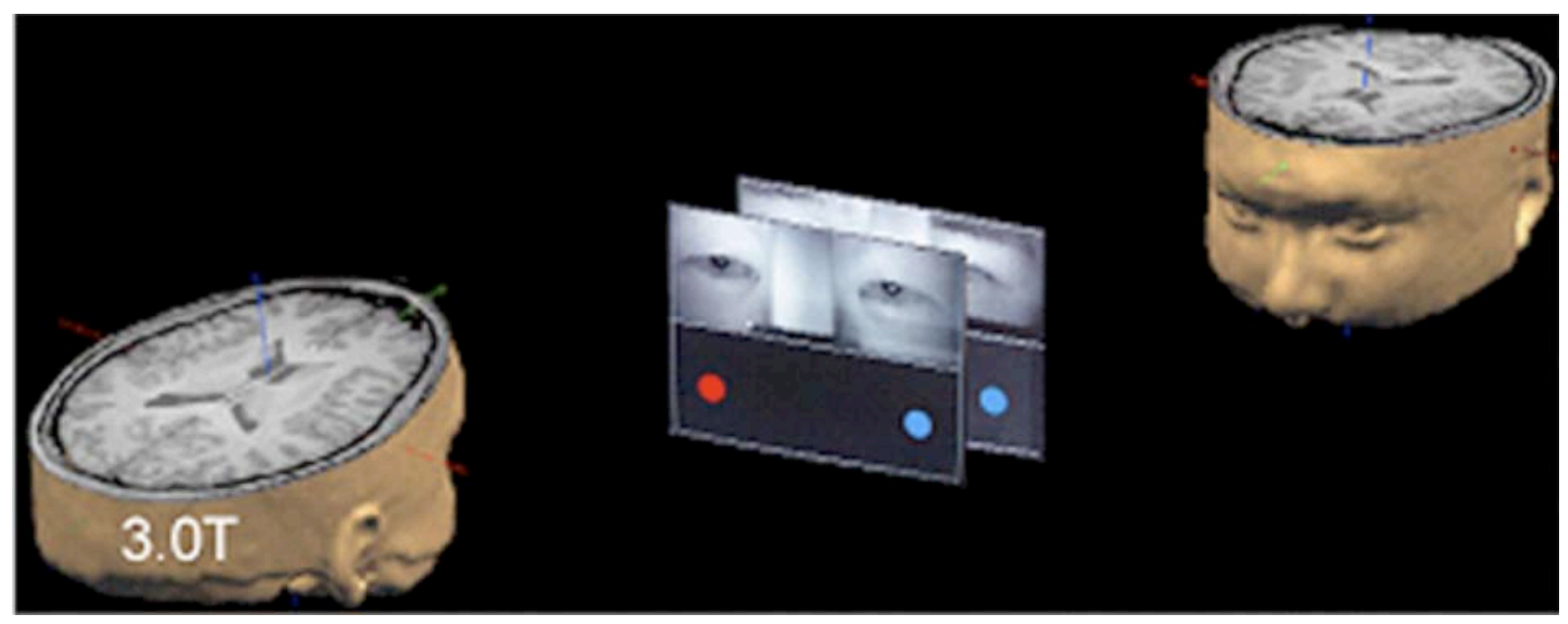

Figure 5. Illustration of the combined hyperscanning \& dual eyetracking setup used by Saito and colleagues (Taken from: Saito et al. 2010).

In a simple task, participants were instructed to either look at (or away from) targets (blue or red balls) when a change in color indicated to do so or to follow (or not follow) the interactor's gaze toward a target. Using this setup for neuroimaging purposes, it was shown that "paired" subjects showed higher correlations than "non-paired" subjects in an area of the MNS as assessed by performing an inter-brain correlation analysis of the blood-oxygen-level-dependent (BOLD) signal time courses as a measure of functional connectivity. Future investigations could use 
measures of effective connectivity to systematically explore both models of eye-movement control as well as measures of inter-brain synchronization (e.g. Schippers et al. 2010; Anders et al. 2011). While we appreciate that the exploratory study by Saito et al. had to rely on a highly structured task, we see a significant number of possibilities for modifying and extending the paradigm and ingenious setup used by the authors.

Indeed, it is only very recently that researchers in social neuroscience have moved on to investigate (relatively) unconstrained real-time social interaction while measuring neural activity in both interactors (Figure 1 C \& D; Figure 2: cube [5]): Dumas and colleagues (2010) set out to investigate the inter-brain correlates of mutual adaptation processes in social interaction by recording with a dual-video and dual-EEG setup while interactors were asked to spontaneously imitate each other's hand movements. Results demonstrated that states of "interactional synchrony", i.e. states during which the hands of the two participants started and ended a movement simultaneously, correlate with a synchronized inter-brain network in the alpha-mu band in centro-parietal cortex. Interestingly, the alpha-mu band has been considered as an electrophysiological correlate of MNS functioning and specific frequencies of this band have been discussed as a marker of social coordination (Tognoli et al. 2007).

Against this background, we posit that a crucial achievement of future research in social neuroscience will consist in the investigation of the neural correlates of mutual adaptation and the reciprocity of human-human social interaction at the intra- as well as the inter-brain level (see Figure $1 \& 2$ ). Beyond the specific methodological challenges regarding synchronized collection and integrated data analysis, a most fundamental challenge involved in this endeavor concerns the implementation of ecologically valid and at the same time highly controllable experimental settings, suitable both for behavioral and neural investigations (cf. Zaki \& Ochsner 2009; Wilms et al. 2010). The state of the art in neuroimaging provides severe limitations to studying freerunning interactions using the full range of verbal and nonverbal channels. Most likely successful studies will need to identify and isolate salient communicative subsystems. As referenced throughout this article human gaze is certainly a most interesting candidate for this type of approach as it is a highly social cue, it can be unobtrusively measured and processed in real-time using modern eyetracking technology and it can be easily experimentally controlled and 
dynamically displayed via artificial characters. Advantages of using virtual representations of human interlocutors in computer animations instead of real-life-interactions or video have long been discussed (see Bente 1989; Blascovich et al. 2002). Early studies using computer-animated characters in observational studies concerned with nonverbal behavior confirmed their external validity, e.g. when comparing impressions of animated characters with video recordings of real people (Bente et al. 2001) and also demonstrated the enormous degrees of freedom in experimental control, e.g. when overlaying the same nonverbal behavior on actors of different gender (Bente et al. 1996) or neutralizing cultural stereotypes by using standardized animation 'dummies' (Bente et al. 2010). However, it is only recently that the advent of sophisticated capture devices for gaze, facial expressions and body movement as well as real time animation tools allow for full character control in the framework of truly interactive research paradigms (Bailenson et al. 2003; Bente et al. 2008a). Using these technologies in such an interactive paradigm, Bente et al. $(2007,2008 \mathrm{~b})$ used motion capture devices, data gloves and eyetracking devices to capture the nonverbal behavior of two interlocutors and transmit this information in real time to the partner's screen where it was executed by an animated character. The whole setting thus established a 'virtual video conference' (see Figure 6).

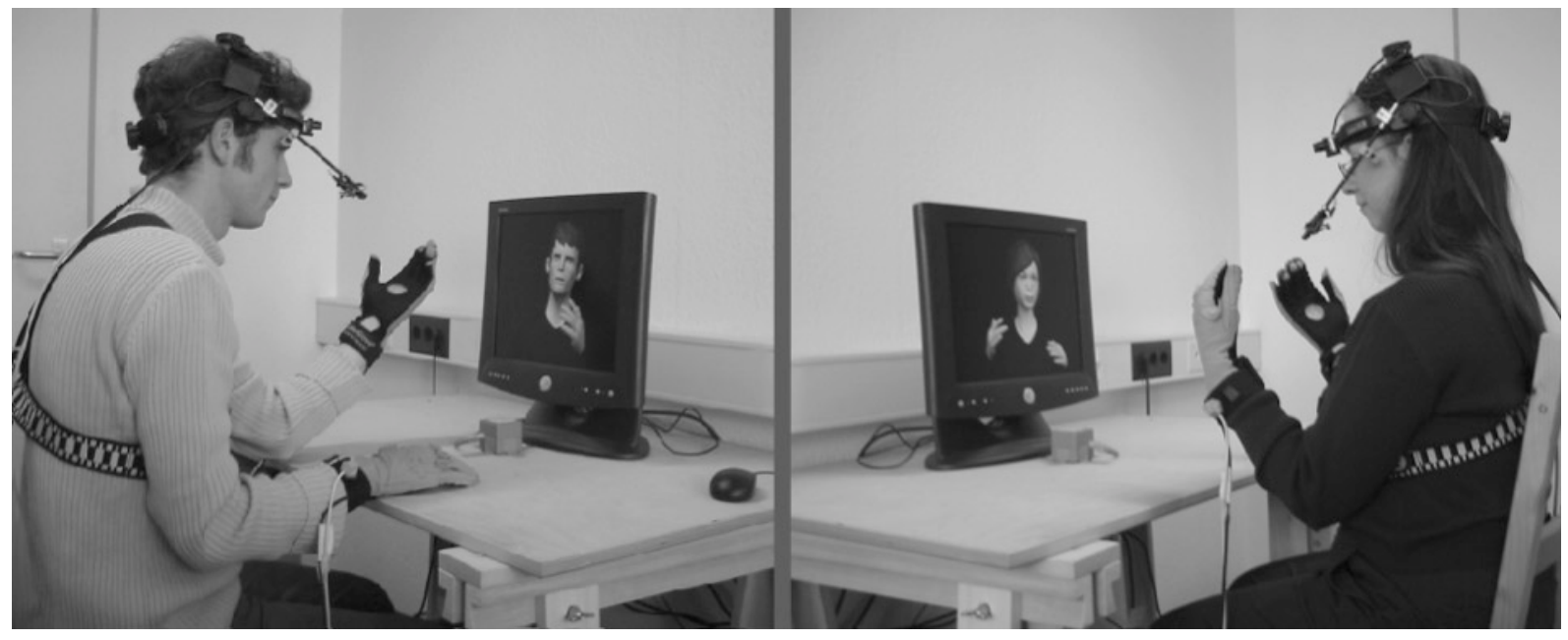

Figure 6. Basic version of an avatar-based interaction platform (screen shot during calibration; virtual 
characters shown on screen are mirroring the interlocutors own behavior).

While movement was left unmodified, gaze was controlled by a computer program, which systematically varied the duration of direct gaze. This kind of "blended interaction" allows for most realistic and lively displays of interaction while exerting strict experimental control over the specific cues under investigation. Furthermore, the computer program can be used to show specific responses conditional on the partner's behavior (e.g. to follow the partner's gaze or not as in Schilbach et al. (2010a), to nod after sentence completion, to show averted or directed gaze after specific key words or nonverbal signals). Beyond these unprecedented possibilities animated characters open for experimental manipulation, they also help to solve problems that arise from the application of complex technologies: Showing the interaction partner lying in a scanner or wearing an EEG cap, carrying reflectors for movement or face tracking might decrease ecological validity more then meeting an avatar in a virtual environment. Measurement devices, however, do not only obscure our view of the interlocutor and provide an awkward image of the other; they also restrict the behavioral repertoire of the actors, for instance the locomotion radius when using a remote eye tracker or the mobility of extremities and head in the fMRI scanner, where actions are often limited to simple key presses. By providing options for an elaborate action repertoire within the constraints of neuroimaging settings, virtual reality or augmented reality setups are, therefore, likely to advance the investigation of the neural underpinnings of joint actions (Knoblich \& Sebanz 2008; Kokal et al. 2010; Newman-Norlund et al. 2007, 2008). On the other hand, the use of (more) mobile data collection devices, such as low-density EEG setups or methods such as functional near infra-red spectroscopy (fNIRS), could also help to overcome some of the bandwidth problems and create more ecologically valid situations, in which participants can use the full range of communicative behavior (e.g. Suda et al. 2010, 2011). Further, using mobile data collection and analysis devices could help to provide real-time visualizations of brain states and investigate how such interactionally presented neuromarkers might contribute to and impact on ongoing social interactions. Finally, another important question will consist in investigating which insights can be gleaned from quantifying inter-brain effects of social interactions and to assess whether two interacting brains provide more information about the interaction than the sum of the individual brains (cf. Hasson et al. 2012). 
Taken together, our review highlights the importance and potential of exploring the neurobiology of social cognition from an interactor's point of view and stresses that the use of more ecologically valid, truly interactive setups will help to address the neural bases of interpersonal coordination and responsiveness in interaction, which may underlie our seemingly effortless ability to apprehend other minds. 


\section{Key Topics \& Objectives for Future Research}

The characterization of differences between social cognition from an interactor's as compared to from an observer's point of view, the differential recruitment of underlying processes and neural mechanisms and the investigation of interacting individuals appear as key targets of a secondperson neuroscience (Figure $1 \& 2$ ). In section 3.2 we have focused on methods necessary for this. The current section highlights how a second-person neuroscience may spark important new questions and can help to shed new light on well-known issues. Here, developing approaches for data collection and analysis from two interacting persons (and possibly two brains) is relevant, as is re-visiting and modifying established experimental paradigms to incorporate an emotionally engaged, interactive perspective (see section 2). This means that, in our view, a second-person account does not replace first- and third-person accounts, but bookends them to a large degree. Consequently, the resulting research questions are concerned with the degree to which the accounts differ, and how they interact with each other (see section 4.1). Furthermore, how is it that largely automatic, implicit forms of interaction develop into explicit social cognitive capacities and how does explicit mind knowledge contribute to ongoing interactions (see section 4.2.1 \& 4.2.2)? Also, if one considers interaction as developmentally prior to mentalizing or mirroring, then the question remains what drives interaction. Here, we focus on the importance of reward signals and motivational processes relevant for participation in social interaction (see section 4.2.3). Finally, we address how insights from a second-person account could be put to use in future research using computational neuroscience techniques and in the emerging field of social neuroendocrinology (see section 4.3). Overall, the next section, therefore, serves to consider potential new avenues that research might take by embracing a second-person approach.

\subsection{Addressing differences between social interaction and observation}

The comparison of processes involved during social cognition from an interactor's versus from an observer's point of view is a central target of a second-person neuroscience. Basically we see three options to address this within the context of measuring a single brain: (a) studies contrasting the information one can obtain when being in interaction with versus observing someone (learning studies); (b) studies contrasting the effects of being in interaction with versus observing someone on subsequent judgments and behavior (priming studies); (c) studies that establish whether we are susceptible to different contextual influences when we are interacting versus observing. 
One way to address the first and perhaps the second type of studies is to look at whether being in an engaged interaction provides the same information as observation, and if not, how this differs. For instance, one could imagine people interacting with a virtual character whereby they have to make judgments on the character or adapt their behavior to her. The question would then be whether differences in participants' learning rates and behavior exist depending upon interacting with the virtual character themselves as compared to seeing someone else interact with the virtual character and what the neural bases of such differences could be. Here, an important hypothesis to pursue is that neural plasticity differences could exist in task-specific neural networks depending upon one's own involvement in interaction as compared to situations when we merely observe others (cf. Cooper et al., in press). Also, it is conceivable that different routes may lead to the activation of a neural network: e.g. in the case of high-functioning autism, patients have failed to show activation differences as compared to healthy controls (Gilbert et al. 2009), which might be related to their ability to activate 'social brain' areas when asked to make a conscious effort to do so. Nonetheless, important differences could exist in situations of naturalistic, fast-paced social encounters and can only be assessed by providing such situations as a test bed. Another important future extension of interactive paradigms will consist in making it possible for two participants to engage in a task and to interact in an experimentally controllable way in a mediated environment. Such a paradigm would allow to control and change the bandwidth of the interaction and could help to systematically perturb an ongoing interaction, e.g. by replaying responses of the other interactor from a previous interaction, and to investigate participants' ability to tell apart "whether the other can see me (or not)". One way in which, we suggest, this could be done would be to make use of a dual eyetracking setup, in which two interactors can be virtually present and perform a task together (e.g. Carletta et al. 2010; Jermann et al. 2010).

Concerning the second type of studies, we suggest that using the established possibility of exploring joint attention in the scanner may help to understand the neural underpinnings of other (possibly more explicit) social cognitive tasks: For instance, it has been suggested that being actively engaged in triadic interaction may have an impact both on the perception of the other person (e.g. his/her trustworthiness and attractiveness) as well as on the perception of an object (e.g. its value) that may be jointly attended (Heider 1958). To the best of our knowledge, there are no neuroimaging studies, which have targeted the neural correlates of the perception of jointly 
attended objects. Such studies might be extremely informative, however, with respect to identifying the neural correlates of different formats or varying degrees of shared intentionality and could also shed light on the complex relationship between implicit and explicit processes involved in social cognition (Frith \& Frith 2008; see also next subsection). Other applications of the method could include investigations of how interactive gaze cues shown by a virtual character impact on object-related decision-making or memory performance. Furthermore, the gaze-based interaction setup could allow to investigate how being involved in an interaction, during which an agent has a high probability of reacting congruently to my gaze behavior by following my gaze, impacts on subsequently presented social cognitive tasks: one particularly intriguing case would be to explore how interaction-based experiences with an agent modulate performance during a subsequently presented task, in which the mental states of the agent (e.g. her desires or beliefs) are reacted to, need to be assessed or explicitly reported. Also, exploring the impact of minimal forms of social interaction on self- and other-related person judgements and the tendency to show pro-social behavior would be particularly relevant and interesting. Apart from asking which processes and tendencies might be primed or enhanced by social interaction, it will also be important to investigate which cognitive capacities might be perturbed or which processes are interfered with during social interaction. Here, an interesting avenue to pursue would be to investigate how being a participant of a social interaction might lead to differential effects on mnestic processes, such that associative components might be favored as compared to declarative memory.

In order to address the third type of studies, one may ask how the situational constraints of a social situation may interact with more abstract rules that one can acquire as illustrated by HFA. When performing social cognition from an observer's standpoint, one might be more inclined to take into consideration cues that inform us about the psychological traits or dispositions of other persons, which may be less closely related to the person's current psychological state and to what the person is actually doing in the precise moment of observation (cf. Jones \& Nisbett 1971). On the other hand, the integration requirements of direct social interaction may be such that —while trying to form an impression of the other - we simultaneously have to adjust and respond to the other person's actions, which means responding to the concretely given and pragmatically relevant aspects of the current situation. While social cognition from an observer's point of view is, therefore, likely to rely more upon situation-independent formats of information (e.g. 
stereotypes), social cognition from an agent's point of view might rely more on making use of situational information in order to make sense of the other's behavior.

\subsection{Social interaction and the relationship of implicit and explicit processes in social cognition}

\subsubsection{From implicit interaction to explicit mentalizing?}

In establishing the relationship between social cognition from an interactor's as compared to an observer's point of view, the question of implicit and explicit processes in social cognition gains further importance. As of today it is largely unclear what the neural signatures of implicit as compared to explicit social cognition are (Frith \& Frith 2008). There is a theoretical as well as an empirical side to this issue, both of which can potentially be elucidated within a second-person account. In theoretical terms, it is not always clear what is meant by "implicit social cognition" and how this is actually related to awareness on the one hand and automaticity versus control on the other. It is never spelled out whether "implicit social cognition" is just what we reason consciously about, minus awareness or, if this is not the case, how exactly the former relates to the latter. For instance, social interaction may be conceptualized as a prime example of implicit learning, as is language, the development of both being closely intertwined (see sections 2.2 and 2.3). As with implicit language learning, an important question is how we develop an explicit and symbolic, or rule-based grasp of language or social interaction based on implicit, predominantly associative learning of statistical regularities. If indeed such explicit knowledge is the result of exposure to increasingly complex social contexts, it remains unexplained how, and what the neural bases of such changes could be. For instance, how do behavioral precursors to TToM develop into a capacity to pass classic TToM tasks?

Ontogenetically, becoming an 'expert' in social cognition may, we suggest, primarily be a question of social interaction while later competencies of more detached, reflective social cognition might be a result of reactivating the networks forged during social interactions and redescribing these interaction-based capacities (cf. Karmiloff-Smith 1992; Cleeremans 2008; Cleeremans et al. 2007). In this respect, our proposal links up with theories about the functional structure of the brain, which take the "re-use" of neural circuitry for various cognitive purposes to be a central organizational principle (e.g. Anderson 2010). According to these theories, it is common for neural circuits to be established for one purpose and then to be put to different uses. 
Crucially, rather than seeing such a re-description as an internally generated, qualitatively different representation of discrete knowledge about the world, our second-person approach frames such a re-description as an ongoing learning process driven by increasingly complex interactive contexts, for instance when moving from dyadic to triadic interaction, which creates the possibility and need to somehow communicate with respect to an external, third object or person (see also Carpendale \& Lewis 2004). Furthermore the involvement of reward signals closely related to ongoing social interaction might also be relevant in this respect (Pasley et al. 2004). Also, in the light of section 2.3, language might in this context not only be shaped by social interaction, but also the other way around, with the gradual development of language providing a scaffolding that allows implicit social know-how to develop in explicit social knowledge. Indeed, as Hutto (2008) suggests, the development from early nonverbal responding to others' mental states, which, according to Hutto, is essentially non-contentful, into explicit, contentful thinking about others' mental states is probably linguistically mediated. Future research in social neuroscience will have to find ways to systematically investigate how activity both in the parieto-frontal cortex and the so-called mentalizing network may be shaped and modulated by the degree to which human observers perceive themselves as participants of social encounters and by actual exposure to social interactions and to understand how this relates to recruiting these networks during observation (Schilbach 2010, cf. Wang et al. 2011).

Apart from investigations of real-time dyadic and triadic interaction in healthy persons, we also see great potential for investigating real-time social interaction in development and diagnostic groups. In spite of the importance of joint attention in ontogeny and a growing number of neuroimaging studies in this respect, the neural correlates of this significant phenomenon and how it unfolds in real-time are incompletely understood. Given that our paradigm does not rely upon verbal information and higher-order reasoning about others' mental states, but relies upon naturally occurring social behavior, it might prove to be particularly useful in this respect and could help to address how human infants come to enjoy the sharing of experiences. Furthermore, a characterization of the neural signature of mutual and joint attention in infancy could be related to the development and neural bases of other social cognitive abilities, which develop later in life to investigate commonalities and differences in a longitudinal setup. Such an approach could help to directly test whether interaction-based network modulations are later co-opted and re-used for higher-order, explicit processes. 
Furthermore, a litmus test for the second-person approach in ontogeny would be to investigate infants' responses to acts of mentality (e.g. intentional actions, attention, emotional facial expressions) depending upon the infant's ability to respond to them when they receive them. Contrary to a simulationist reading, which would predict that infants need to be able to do the actions themselves, and to "mind-reading" accounts, which hold that the infant needs to be able to observe and conceptualize patterns in order to be able to grasp actions meaningfully, the second-person approach suggests that acts of mentality should be meaningful to infants depending on the infant's ability to respond to them when they receive them, regardless of whether the infants can do the actions themselves.

Thus, a second-person neuroscience will be concerned with the question of how direct social interaction with others - and the implicit processes inherent to this - may inform and modulate more detached, explicit perspectives on them. Evidence from developmental psychology has been taken to suggest that reflective (or 'meta-cognitive') competence emerges through the infant's social interactions with others by relating one's own states with those of others (e.g. Rochat \& Striano 2002). However, a more radical approach holds that it may be only via social interaction and in virtue of the fact that we are constantly trying to model other minds in interaction that we learn to be conscious and develop both an understanding of ourselves and a conscious percept of the world at all (Cleeremans 2011). A study by Bahrami and colleagues (2010) further indicates that such interaction-based improvements of introspective abilities continue to be effective during adulthood.

\subsubsection{From mentalizing and mirroring to automatic interaction?}

A question equally important to an ontogenetic account is how we manage to engage in interaction on a daily basis, without referring to explicit knowledge. Instead, we interact and 'go with the flow', all the while retaining the capacity to reflect upon our interlocutor and ourselves afterwards. It is exactly here that neurobiological evidence of TToM-related activations has given rise to the idea of "implicit TToM" or "implicit social cognition". But if this "implicit TToM" is essentially something different than what we consciously deploy in False Belief tasks, say, then what does it represent? It is here that the most immediate empirical questions may be raised: are the implicit and explicit processes that occur in interaction actually the same processes as those 
that occur during observation? We suggest that this may not be so, in that interaction-based processes involve at least two aspects. First, they involve an automatic inference component based on previously acquired knowledge, which is also present during observation, and which is largely impervious to explicit modification. Second, they also require an action-control component, which can be fast $(<350 \mathrm{~ms})$ and based on the previously acquired knowledge, or slightly slower (>350ms) and potentially available to control (Khan et al. 2003; Pisella et al. 2000; Rossetti et al. 2003; Sartori et al. 2009). As such, whereas during interaction implicitly activated knowledge seems to be immune to explicit interference (Ambady et al. 2000; Choi et al. 2005), automatic processes are - due to their action component - susceptible to explicit modification, or interference (you drive a car or play a musical instrument without thinking about particular movements contributing to it, but you can to some degree bring them under conscious control - which under normal circumstances will hamper fluent performance). However, such awareness of action is related not only to action preparation (motor signal), but is additionally prone to strong reconstructive effects of the sensory consequences of one's actions (Haggard 2009; Haggard \& Tsakiris 2009; Sarrazin et al. 2008; Pacherie 2008; Sato \& Yasuda 2005). In an observational context, such factors simply do not come into play, whereas in an interactive context, this means that the reactions of the other co-determine the degree to which one becomes conscious of one's actions, to which anyone who ever committed a serious gaffe in public will readily testify.

An illustration of how the reasoning described above might lead to novel approaches lies in psychiatric disorders: for instance, autistic persons have been described as having problems with implicit or intuitive social cognition. However, in terms of elementary processes, several studies have been unable to find problems with implicit learning (Brown et al. 2010), action representation (Sebanz et al. 2005), or even mirroring (Southgate \& Hamilton 2008). Thus, one empirically verifiable possibility would be that, at least in HFA, both low-level and high-level processes are relatively intact, but that the application of this implicit know-how versus explicit knowledge is disturbed, in that persons with HFA apply explicit, high-level TToM in situations where healthy controls 'trust a gut feeling'. This then could lead to the hypothesis that HFA persons lack the know-how or knowledge that would subtend such a gut feeling (their explicit knowledge not being rooted in interactive know-how), or, alternatively, that they fail to recognize and trust such a gut feeling and instead, in any task allowing explicit reasoning, will opt for such 
explicit rules instead (failure of automatic application of knowledge, whether know-how or explicit knowledge). Crucially, the notion of how these potentially different capacities, implicit learning and automatic behavior contribute to autism -and healthy controls- remains elusive in passive spectatorial settings.

\subsubsection{Motivation and the spark to interaction: Putting reward signals into social cognition}

Another important feat will be to address how motivation- and reward-related signals could be differentially engaged during participation in social situations as compared to observation of others' interaction and might interact with brain regions relevant for action control (cf. Pessoa \& Engelmann 2010; Oullier \& Basso 2010; Schonberg et al. 2010; Figure 1). This directly follows from our conception of 'active' social perception strongly relying upon affective and rewardbased contingencies that result from being personally addressed and prompt responses, which feed into ongoing social interaction. Being in the presence of someone, human beings cannot help but interact with each other (e.g. Zwickel \& Vo 2010), which may be due to an evolutionary heritage of depending upon others for survival possibly having rendered social interaction 'intrinsically' rewarding (Coan 2008; Tomasello 2009). Consequently, being a participant (as compared to being an observer) of social interaction, we speculate, might also lead to an expectation of reciprocation that is more in line with cooperative than competitive behavior and motives (Pfeiffer et al., in press). Furthermore, human beings appear to be extremely sensitive to having an impact on conspecifics and seem to enjoy exerting such influence from early on in life (Fiske \& Dépret 1996; Gergely \& Watson 1996; Schilbach et al. 2010a). Relatedly, human beings not only enjoy being imitated by others (as long as this is done covertly), but this also increases feelings of affiliation and rapport (Chartrand \& Bargh 1999). Consistently, experiences or even hints of social exclusion (even third-party exclusion) increases affiliative imitation (Over $\&$ Carpenter 2009). One of the factors that make exerting an influence on other persons so rewarding, might be their agentivity: first, it vastly increases the action possibilities of the other, and hence the uncertainty of what the effect of my action will be (compared to when I interact with, say, a vending-machine); second, it might be that simply knowing that the other is an independent agent having other options than reacting to you, makes a contingent response very rewarding.

To investigate interactions of motivation- and reward-related signals with activity in action 
control and social cognition networks during participating in social interaction, we have devised a non-verbal Turing test, which is based on the interactive eyetracking paradigm used to investigate joint attention described in section 3.1.2. In this setup participants engage in gaze-based interaction with an anthropomorphic virtual character, whose gaze behavior is said to be controlled by another participant or by a computer, while, in fact, it is always controlled by a computer algorithm. Using this setup, the character's gaze reactions were systematically varied along a continuum from a maximal probability of gaze aversion to a maximal probability of gazefollowing during brief interactions, thereby varying congruency and contingency of the reactions. We investigated how these variations influenced whether participants believed the character to be controlled by a person or a computer. In a series of experiments, the confederate was either introduced as "naïve" to the task, "cooperative" or "competitive". Results demonstrate that the ascription of agency increases with higher congruency of gaze reactions when participants are interacting with a "naïve" partner. In contrast, agency ascription was driven by the degree of contingency (i.e. the probability of the virtual other reacting) irrespective of congruency (whether or not the behavior shown in response was the same or different from the participant's) reactions when the confederate was introduced as "cooperative". Conversely, during interaction with a "competitive" confederate, judgments were neither based on congruency nor on contingency (Pfeiffer et al., in press). These results offer important insights into what renders the experience of an interaction truly social: Humans appear to have a default expectation of reciprocation as evidenced by the naïve condition, which can be influenced drastically by the presumed disposition of an interactor to cooperate or compete. This finding, we assume, could be related to our neuroimaging results, which were accrued by making use of the same kind of paradigm and highlight the involvement of reward-related neurocircuitry during congruent interactions (Schilbach et al. 2010a). The use of the Turing test paradigm for neuroimaging purposes is likely to advance our understanding of the neural bases of social interaction: For example, it can hypothesized that gaze-based interaction with a naïve confederate might lead to an increase in neural activity in areas of the so-called mentalizing network while conditions with highly congruent reactions might lead to an increase in reward-related brain areas. While competitive interactions might also lead to an increase of neural activity in mentalizing areas, it will be interesting to investigate whether a competitive context could also lead to a decrease of activity in reward-related neurocircuitry. Also, the question can be targeted whether the presence of a shared goal (as in the cooperative context), leads to a decrease of activity in the mentalizing system 
while concomitantly an increase of activity might be observed in regions, which have been implicated in coordinated behavior. Furthermore, it will be interesting to investigate whether changes in activity of the brain's reward system in response to positively contingent gazereactions could generalize to contingent reactions irrespective of their valence depending on the situational context. Finally, neuroimaging studies, which make use of this paradigm, may help to investigate putative connectivity differences between relevant brain areas during social interaction (Figure 1), which could help to understand the neural bases of opposing effects between imitative behavior and understanding of others' minds (Stel et al. 2009).

Recent evidence suggests that different reward types recruit the reward system of the brain, which has given rise to the suggestion of a 'common neural currency' for rewards (Izuma et al. 2008). The neural mechanisms of differences in the susceptibility for different types of reward, however, remain unclear. Also, it is not well known how different reward types may compete and can act as a surrogate for one another (e.g. using food rewards when other rewards are unavailable) or how social influences may serve as a control mechanism to reward dependency. In order to probe the reward system of the brain while at the same time allowing for the use of different reward stimuli, the interactive eyetracking paradigm could be adapted to serve as a reward-based saccade paradigm. In such a paradigm participants would be asked to generate and be rewarded for successfully completing saccades to visual targets. Rewards could be varied to include monetary, food and social rewards (congruent gaze reactions of an anthropomorphic virtual character also shown on the stimulus screen). On the behavioral level higher reward probability for a given target is expected to lead to a decrease in saccade latencies (e.g. Milstein \& Dorris 2007), whose magnitude may depend upon the specific reward type. On the neural level, the correlates of this reward-related bias and possible reward type-specific differences in controls and patient groups characterized by social impairments (such patients with autism and schizophrenia) are not well known. Research in non-human primates suggests that midbrain dopamine neurons involved in motivated saccade tasks receive inputs from many brain areas including the ventral and dorsal striatum, the subthalamic nucleus, the amygdala, the lateral hypothalamus, the dorsal raphe nucleus and the lateral habenula (Matsumoto \& Hikosaka 2009; Bromberg-Martin et al. 2010). A comparison of different reward types could not only allow to investigate overlap and differences in the underlying neural correlates, but could also allow to calculate a scaling factor (i.e. an 'exchange rate') between social, monetary and food rewards for 
each subject.

\subsection{An applied second-person neuroscience}

\subsubsection{Computational social neuroscience}

While computational neuroimaging studies inspired by game theory and others, which use generative models for data analyses, have already taken up the investigation of competitive scenarios and are beginning to address cooperative games (e.g. Yoshida et al. 2008), human beings' unparalleled abilities for cooperation in real-time social interaction have largely been left unexplored. Here, extending computational social neuroscience approaches to reciprocal and adaptive two agent-interactions holds great potential for future research and may allow to investigate how differences in perspective towards others, i.e. social cognition from an agent's versus from an observer's point of view, may influence the reliance on different computational mechanisms. For instance a study by Hampton et al. (2008) demonstrates the importance of representing the possible influence one may have on others in direct interaction. Similarly, recent findings from model-based neuroimaging studies already do provide evidence for differences in the neural mechanisms of experienced as compared to observational learning (activity changes in ventral striatum being selective to instrumental actions; Cooper et al., in press). Computational approaches will be particularly powerful in helping to address the history of an ongoing social interaction and how learning may occur and unfold. In doing so, model-based analysis of neuroimaging data could help to investigate the development of neural networks, their structural and neurofunctional underpinnings, during social interaction, thereby helping to understand how particular functions develop in particular areas of the brain or specifically the brains of interacting minds. One example of how a computational social neuroscience paradigm may help to assess and quantify the impact of (gaze-based) social interactions is the following: By combining a cooperative game such as the 'stag hunt' game developed by Yoshida and colleagues (2008) with a gaze-based social interaction manipulation (Schilbach et al. 2010a), it becomes feasible to test computational models under more ecologically valid conditions. In light of our hypothesis and preliminary findings, which suggest that social interactions may prompt

collaborative motives, we expect that congruent gaze behavior exhibited by the virtual character in our joint attention manipulation may promote cooperative behavior in the 'stag hunt' game, while gaze aversion of the virtual character may have the opposite effect. Using fMRI while participants are involved in gaze-based interactions and in the stag hunt game may also allow to 
use correlational approaches and multi-variate pattern analysis to predict the level of cooperation in the stag hunt from neural activity observed during gaze-based interaction.

Alternatively, future studies could use more elaborate models to control the behavior of a virtual character (conversational agents) in more complex ways (e.g. Kelso et al. 2009; Triesch et al. 2006, 2007; Broz et al., in press). The meaningful use of conversational agents, i.e. completely computer generated artificial social entities, in interaction studies, in contrast to avatars would require the implementation of basic social skills in the agents, serving the perception, processing and production of interactive behavior (see Vogeley \& Bente 2010). Such implementations are feasible if the scope of behavior is constrained with regard to channel bandwidth (e.g. to eye gaze) as well as with regard to the task affordances (e.g. fixation of objects, gaze following, etc). However, the available technologies are far from allowing for broadband interactions in open conversational situations. Using such an approach might provide a most informative complementarity to recent investigations, which have focused on using computational models to predict neural responses in a human observer or interactor (e.g. Behrens et al. 2009; Cooper et al., in press) and could help to explore the explanatory power of mutually adaptive modeling approaches.

\subsubsection{Genotype-specific effects and hormonal influences of the neural basis of social interaction}

Recent evidence suggests that important hormonal influences exist, which can specifically affect social behavior and its underlying neuroanatomical and neurofunctional correlates (e.g. Chura et al. 2010; Hermans et al. 2010; Volman et al. 2011), giving rise to the notion of a field of 'social neuroendocrinology' (cf. Bos et al. in press). Interestingly, it has been suggested that certain hormonal responses only occur in ecologically valid situations (e.g. Henckens et al. 2009), which is consistent with the assumptions of the here proposed second-person approach. Therefore, it seems likely that using the types of interactive and ecologically valid paradigms endorsed by the second-person account may also help to advance the investigation of the complex interplay and influence of hormones on the 'social brain'. In addition, efforts are also being undertaken to understand genotype-specific differences in prosocial hormones and brain anatomy and how they impact on social behavior (e.g. Tost et al. 2010; Chen \& Johnson, in press). Furthermore, we see great potential in elucidating how such genotype-specific differences might be related to differences in reward-based processing (e.g. Chakrabarti \& Baron-Cohen 2011) and could predict 
differential responses to pharmacological challenges or therapeutic interventions. In the following, we, therefore, go on to discuss the possible implications of a second-person approach to other minds for our understanding of psychiatric disorders. 


\section{Impact}

\subsection{Psychiatric disorders as disorders of social cognition}

It has increasingly been recognized that we can conceive of psychiatric disorders as disorders of social cognition (e.g. Crespi \& Badcock 2008; Vogeley \& Newen 2009). ${ }^{4}$ While there is great merit to be found in this endeavour, the above described conceptual and empirical developments may be taken to suggest that previous research inspired by this assumption may have overemphasized explicit forms of social cognition while recent work, we suggest, indicates that related impairments might be more closely linked to difficulties in skillfully engaging in social interaction (Schilbach et al., in press).

\subsection{The case of high-functioning autism}

"Direct interaction always leads to complications."

Patient M.V.

\subsubsection{The impact of social gaze on action control and interpersonal coordination in high-} functioning autism

Autism is characterized by qualitative impairments of social interaction and communication. Here, the distinction between implicit and explicit processes has recently been emphasized: contrary to popular explanations, what seems to be impaired in high-functioning autism (HFA) is not the ability to use explicit mentalistic inference, but rather the implicit processes which contribute to participating in social interaction and which allow us to orient towards and automatically integrate relevant social cues in more complex situations (Becchio et al. 2007; Senju et al. 2009; Kuzmanovic et al. 2011). Individuals with HFA are neither impaired in explicit social cognition - as they, in fact, consciously remind themselves to think about the mental states of others in an attempt to compensate for interaction difficulties - nor in their capacity of implicit learning in general (Brown et al. 2010). Instead they may lack the more basic skills to respond intuitively to socially relevant information by generating "adaptive actions upon salient

\footnotetext{
$4 \quad$ While an in-depth analysis of this particular issue is clearly beyond the scope of this article, we would like to note that from our standpoint the suggestion of a second-person approach to other minds is consistent with an integrative account of psychopathology, which takes into account and weighs data gathered by means of various methods, by observation of and in interaction with the patient and those around her in an attempt to explore convergences of naturalist and normative reasoning.
} 
aspects of the environment" (Klin et al. 2003). The discrepancy between the ability to solve explicit social cognitive problems and the inability to meet the demands of everyday life social interactions in HFA has been highlighted by methods, which allow probing involuntary aspects of behavior. The difference between explicit and implicit social cognition is also nicely captured by descriptions of subjective experiences that persons with HFA provide. Here, individuals with HFA emphasize a preference for being in an observational stance towards others as this allows to 'logically compute', 'contemplate' and 'think through' aspects of the situation in a conscious and cognitively effortful way. Furthermore being an observer also allows to think about what one may know about a given situation and the constraints this may entail for a person who is actually in it. On the contrary, the situation becomes remarkably different and more complicated for a person with HFA when the person she has quietly been observing turns toward her and tries to engage her in interaction. Here, patients describe 'being flooded' by information, an 'inability to keep up' and 'not knowing when and how' to respond to what others do possibly due to the imperfect contingencies inherent to social interaction (Klin et al. 2009).

We suggest that the impairments of being able to respond intuitively to socially relevant information could be closely related to the ability to perceive social affordances, i.e. the possibilities for interaction provided by others. In order to investigate the impact of social cues on mechanisms of action control, we, therefore, made use of a stimulus-response compatibility (SRC) paradigm, in which control and HFA participants were asked to generate spatially congruent or incongruent motor responses to changes in a face, a face-like and an object stimulus (Schilbach et al., in press). Results demonstrate that while in control participants being looked at by a virtual other leads to a reduction of reaction time costs associated with generating a spatially incongruent response, this effect is not present in the HFA group. We suggest that this modulatory effect of social gaze on action control in control participants might be related to social cues triggering motor preparatory programs that may help to coordinate one's actions with those of someone else, rather than providing a mere 'resonance' mechanism. It is conceivable that participants thereby automatically adjust to the 'perspective' of the virtual agent by making sense of the situation in pragmatic terms (Sebanz et al. 2006). Hereby, an action that is deemed spatially 'incongruent' from an allocentric observer's point of view might end up being 'complementary' to what the participant perceives the (virtual) other do. In other words: being in the presence of someone else (even a virtual other) may change our perception of the 
environment towards perceiving it in terms of the resources or possibilities for actions held collectively ("we-space”), rather than individually (e.g. Krueger 2010).

Consistent with the above described interpretation of social cues leading to a recruitment of motor-preparatory and action-monitoring-related processes, an fMRI study from our lab using an abridged version of the social SRC paradigm in a group of healthy participants, indeed, demonstrated that performing incongruent actions in the presence of a virtual other (as compared to performing them in response to a non-social stimulus) leads to a differential increase of neural activity in brain regions known to be involved in action monitoring and response inhibition (anterior cingulate cortex and inferior frontal gyrus), but also areas previously implicated in social cognition (dorso-medial prefrontal cortex; see Schilbach et al. 2010b for details). Furthermore, reaction time differences between the social and non-social condition appear to be closely related to activity changes in the reward system of the brain as measured by BOLD fMRI: participants who demonstrated more pronounced activations of the ventral striatum -often related to hedonic or rewarding experiences - also found it more difficult to disengage from the face stimulus in order to generate incongruent motor responses, which is consistent with suggestions of an important influence of reward-related processes on mechanisms of action control (cf. Pessoa \& Engelmann 2010). Taken together, these results highlight that performing actions in a - albeit minimal - social context significantly affects mechanisms of action control (Schilbach et al. 2010b, 2011; Gangopadhyay \& Schilbach, in press).

Our findings are consistent, therefore, with the proposal of difficulties in the automatic integration of social information in HFA while more explicit measures of social cognition may be intact as a result of compensatory strategies (Senju et al. 2009; Kuzmanovic et al. 2011). Whereas control participants respond to the virtual agent's gaze by a differential recruitment of motorbased processes leading to a performance benefit as compared to the object stimulus and by recruitment of the brain's reward system possibly relevant for the hedonic experience of social as compared to non-social stimuli, our results seem to suggest no such difference in HFA. In other words, individuals with autism may not lack a theory of how other minds work ('knowing that'), but the relevant 'know-how' for dealing with others in direct interaction (cf. Zahavi \& Parnas 2003). Also, important differences are likely to exist in the degree to which social interactions can evoke comparable responses in reward-related neurocircuitry in patients with HFA (cf. 
Schultz 2005).

In line with the second-person approach, future research should, therefore, investigate impairments of social cognition in autism as reflecting difficulties in skilfully interacting with others as those might be at the very heart of the problems faced by patients in everyday-life social encounters. We suggest that the investigation of the neural mechanisms underlying these clinically relevant differences in high-functioning autism will benefit substantially from using more ecologically valid paradigms that look at how people actively engage and interact with one another in social encounters. Furthermore, it will be important to relate known differences in structural (Catani et al. 2008) and functional connectivity in autism (Kennedy et al. 2006) to interaction abilities. Here also, connectivity differences in the mentalizing or default mode network (see section 3) and the anti-correlated fronto-parietal network as well as interactions of both networks with the reward system of the brain (Camara et al. 2008) appear as primary candidates for such studies. Using paradigms that allow control of the bandwidth of the social interaction may help to titrate levels of perceptual complexity and differences in the temporal structure of an interaction in order to adapt to the differences in functional and structural connectivity and concomitant interaction requirements. Also, using mediated social interactions could help to provide additional cues for patients to facilitate the interaction.

\subsubsection{Language use in high-functioning autism}

According to the view of 'language-as-action' or of language as a 'tool for social interaction' (Tylen et al. 2010), language processing can be regarded as a joint activity, which results in entrainment and synchronization between partners on various levels (Pickering \& Garrod 2004). Furthermore, this 'grounding' view of language suggests that words do not contain their meaning, but that linguistic labels can be highly negotiable and that interlocutors flexibly seek to understand them against the background of a 'common ground' (Clark 1996). To this end interlocutors produce and monitor paralinguistic cues and one another's instrumental behavior to ensure they, indeed, understand each other. This view of language processing in dialogue whereby a partner's contribution plays a dual role by providing the other person with evidence of how the previous utterance has been understood - resonates with our proposal of a secondperson approach to other minds, which also highlights the importance of reciprocal relations and their partially constitutive role in interpersonal understanding. Here, the various feedback from an 
interaction partner and bouts of interpersonal synchronisation shape and structure the 'interaction space' and the denouement of the social encounter.

In high-functioning autism several language-related abnormalities are present, which, we believe, can be best understood in terms of the 'grounding' rather than the 'message model' view of language processing: Individuals with high-functioning autism -in spite of their elaborate linguistic code and in the absence of developmental language delay in Asperger's syndromehave profound difficulties in understanding irony and insist on the use of the literal meaning of words, for which a more 'objective', rule-based, situation-independent and 'correct' usage can be determined. Consequently, the language in high-functioning autism is characterized by pragmatic and semantic deficits with patients being less likely to integrate contextual information (Groen et al. 2010). Consistently, patients seem to have particular difficulties in adapting to the changes in linguistic labels in reference to an immediately given social context (Nadig et al. 2009). While in normal controls language promotes interpersonal coordination by helping to coordinate attention even in the physical absence of an interlocutor (Richardson et al. 2007; Tylen et al. 2010), the same does not appear to be true for individuals with high-functioning autism. Patients commonly describe difficulties in maintaining telephone conversations due to the fact that they find it nearly impossible to know when to speak in the absence of visual cues. While - in summary - the predominantly information-based functions of language (as described by the 'message model' of language) seem to be intact in high-functioning autism, it is the socially constructed and interactionally coordinative functions of language, which operate on a more implicit and automatic level, that appear to be most impaired (Pexman et al. 2010).

\subsubsection{Meeting the interaction requirements of patients with high-functioning autism}

From a clinical perspective, individual reports of patients with HFA from our outpatient clinic are also noteworthy, in that patients describe not having any significant impairments of social interaction and communication when they interact with other persons diagnosed with HFA, which stands in striking opposition to the difficulties, which systematically occur when they interact with persons without this diagnosis. While also raising issues about the normative aspects of psychiatric diagnoses, these anecdotal reports emphasize that successful interaction and communication are crucially a matter of interpersonal adjustments and (possibly) an awareness of the interactional requirements of another person. Investigating these issues in patients with 
autism, we suggest, might help to improve not only psychotherapeutic interventions, but could also help to substantially raise public awareness thereby promoting flexibility and openness to diversity in styles of social interaction. This is especially crucial for the case of HFA: As we are normally not aware of our intuitive, nonverbal capacities that are automatic in nature, we do not even have the chance to take notice of the specific deficits in the communicative behavior of HFA patients. With respect to the focus of this paper, namely the scientific investigation of realtime social interactions, it seems most interesting to contrast dyads of neurotypical persons with neurotypical-patient and patient-patient dyads. Investigations of the latter type might help to shed light on the neural mechanisms, which allow for successful interactions between persons known for their social interaction impairments. Also, the study of differences in social interaction dynamics could prove to be a promising route and might be developed into a tool for helping differential diagnosis in psychiatric disorders. 


\section{Concluding remarks}

In this article we have argued for the conception of a second-person approach to other minds suggesting that interpersonal understanding is primarily a matter of social interaction and emotional engagement with others. We suggest that this account — well-grounded in current philosophical considerations - provides a different route to the investigation of intersubjectivity by emphasizing aspects of social cognition specifically related to the procedural nature and experiential aspects of social interactions. Furthermore, we have argued for the application of this approach to the neurobiological investigation of social cognition based on our analysis that 'dark matter' in social neuroscience remains due to difficulties of investigating and conceptualizing real-time social interactions. A second-person neuroscience will, therefore, make use of innovative experimental setups to investigate social interaction and its relationship to social cognitive abilities in more ecologically valid ways. Such developments will not only help neuroscience to really go social, but may also be relevant for our understanding of psychiatric disorders construed as disorders of social cognition.

While preliminary neuroscientific evidence suggests that social cognition is, indeed, fundamentally different when we are engaged with others, embedded in social interaction, many questions remain unanswered. Studies are needed to directly compare social cognition from an interactor's versus from an observer's point of view. How do putative differences with respect to the reliance on underlying mechanisms relate to the large-scale neural networks that are known to be involved in social cognition? The use of ecologically valid paradigms to probe social cognition, we suggest, will help to elucidate their putatively complementary roles as a function of the pragmatic requirements of social interaction and may also help to understand how activity might be shaped by the dynamics and 'history' of an ongoing interaction. Here, the interaction of gaze and other action-related cues will be of paramount importance. Also, studying cooperative and competitive interactions in an ecologically valid, emotionally engaged way will be important to spell out the functions of active participation and reciprocity in social interaction and how they relate to our perception of the human status of an agent. Neither do we know as yet, what the relative contributions and neuronal bases of implicit and explicit ways of understanding others in interaction as compared to observation are, nor how this may relate to cases of psychiatric disorders, which can be thought of as disorders of social cognition. Finally, the precise role of 
reward signals in social cognition needs to be investigated since they could constitute an important driving force for participation in social interactions and could crucially influence other aspects of cognition and processes of self-regulation.

By taking social interaction and a second-person approach to knowing minds seriously, future investigations in- and outside the field of social neuroscience are likely to provide radically new insights into the psychology and neurobiology of how we know other minds and will produce evidence for an interactive account of social cognition that emphasizes the constitutive role of participating in the social world. 


\section{References}

Allen, M. \& Williams, G. (2011) Consciousness, plasticity, and connectomics: The role of intersubjectivity in human cognition. Frontiers in Psychology 2:20. http://dx.doi.org/10.3389/fpsyg.2011.00020

Allport, F. H. (1924) Social psychology. New York: Houghton, Mifflin.

Ambady, N., Bernieri, F. \& Richeson, J. (2000) Towards a histology of social behavior: Judgmental accuracy from thin slices of behavior. Advances in Experimental Social Psychology 32:201-72. http://dx.doi.org/10.1016/S0065-2601(00)80006-4

Amodio, D. M. \& Frith, C. D. (2006) Meeting of minds: the medial frontal cortex and social cognition. Nature Reviews Neuroscience 7(4):268-77. http://dx.doi.org/10.1038/nrn1884

Anders, S., Heinzle, J., Weiskopf, N., Ethofer, T. \& Haynes, J. D. (2011) Flow of affective information between communicating brains. Neurolmage 54(1):439-46. http://dx.doi.org/10.1016/j.neuroimage.2010.07.004

Anderson, M. L. (2010) Neural reuse: A fundamental organizational principle of the brain. Behavioral and Brain Sciences 33(4):245-66. http://dx.doi.org/10.1017/S0140525X10000853

Asch, S. (1952) Social psychology. Englewood Cliffs, NJ: Prentice-Hall.

Auvray, M., Lenay, C. \& Stewart, J. (2009) Perceptual interactions in a minimalist virtual environment. New Ideas in Psychology 27:32-47. http://dx.doi.org/10.1016/j.newideapsych.2007.12.002

Bacharach, M. (2006) Beyond Individual Choice. Princeton University Press.

Bahrami, B., Olsen, K., Latham, P. E., Roepstorff, A., Rees, G. \& Frith, C. D. (2010) Optimally interacting minds. Science 329(5995):1081-5. http://dx.doi.org/10.1126/science.1185718

Bailenson, J. N., Blascovich, J., Beall, A. C. \& Loomis, J. M. (2003) Interpersonal distance in immersive virtual environments. Personality and Social Psychology Bulletin 29(7):819-33. http://dx.doi.org/10.1177/0146167203029007002

Bar, M. (2007) The proactive brain: Using analogies and associations to generate predictions. Trends in Cognitive Sciences 11(7):280-9. http://dx.doi.org/10.1016/j.tics.2007.05.005

Barresi, J., Moore, C. (1996) Intentional relations and social understanding. Behavioral and Brain Sciences 19(1):107-22. http://dx.doi.org/10.1017/S0140525X00041790

Becchio, C., Pierno, A., Mari, M., Lusher, D. \& Castiello, U. (2007) Motor contagion from gaze: The case of autism. Brain 130(9):2401-11. http://dx.doi.org/10.1093/brain/awm171

Becchio, C., Sartori, L. \& Castiello, U. (2010) Toward you: The social side of actions. Current Directions in Psychological Science 19(3):183-8. http://dx.doi.org/10.1177/0963721410370131

Behrens, T. E., Hunt, L. T. \& Rushworth, M. F. (2009) The computation of social behavior. Science 324(5931):1160-4. http://dx.doi.org/10.1126/science.1169694

Bente, G. (1989) Facilities for the graphical computer simulation of head and body movements. Behavior 
Research Methods, Instruments, \& Computers 21(4):455-62. http://dx.doi.org/10.3758/BF03202817

Bente, G., Eschenburg, F. \& Aelker, L. (2007) Effects of simulated gaze on social presence, person perception and personality attribution in avatar-mediated communication. Proceedings of the 10th Annual International Workshop on Presence. http://www.temple.edu/ispr/prev_conferences/proceedings/2007/Bente,\%20Eschenburg,\%20and\%20Aelk er.pdf

Bente, G., Feist, A. \& Elder, S. (1996) Person perception effects of computer-simulated male and female head movement. Journal of Nonverbal Behavior 20(4):213-28. http://dx.doi.org/10.1007/BF02248674

Bente, G., Krämer, N.C. \& Eschenburg, F. (2008b) Is there anybody out there? Analyzing the effects of embodiment and nonverbal behavior in avatar-mediated communication. In: Mediated Interpersonal Communication, eds. E. Konijn, S. Utz, M. Tanis \& S. Barnes (pp. 131-57). Mahwah, NJ: Lawrence Erlbaum Associates.

Bente, G., Krämer, N. C., Petersen, A. \& de Ruiter, J. P. (2001) Computer animated movement and person perception: Methodological advances in nonverbal behavior research. Journal of Nonverbal Behavior 25(3):151-66. http://dx.doi.org/10.1023/A:1010690525717

Bente, G., Leuschner, H., Al Issa, A. \& Blascovich, J. J. (2010) The Others: Universals and cultural specificities in the perception of status and dominance from nonverbal behavior. Consciousness and Cognition 19(3):762-77 http://dx.doi.org/10.1016/j.concog.2010.06.006.

Bente, G., Rüggenberg, S., Krämer, N. C. \& Eschenburg, F. (2008a) Avatar-mediated networking: Increasing social presence and interpersonal trust in net-based collaborations. Human Communication Research 34(2):287-318. http://dx.doi.org/10.1111/j.1468-2958.2008.00322.x

Bigelow, A. \& Rochat, P. (2006) Two-month-old infants' sensitivity to social contingency in motherinfant and stranger-infant interaction. Infancy 9(3):313-25. http://dx.doi.org/10.1207/s15327078in0903_3

Biocca, F., Harms, C. \& Burgoon, J. (2003) Toward a more robust theory and measure of social presence: Review and suggested criteria. Presence: Teleoperators \& Virtual Environments 12(5):456-80. http://dx.doi.org/10.1162/105474603322761270

Blascovich, J., Loomis, J., Beall, A. C., Swinth, K. R., Hoyt, C. L. \& Bailenson, J. N. (2002) Immersive virtual environment technology as a methodological tool for social psychology. Psychological Inquiry 13(2):103-24. http://dx.doi.org/10.1207/S15327965PLI1302_01

Bos, P. A., Panksepp, J., Bluthe, R. M. \& Honk, J. V. (in press) Acute effects of steroid hormones and neuropeptides on human social-emotional behavior: A review of single administration studies. Frontiers in Neuroendocrinology. http://dx.doi.org/10.1016/j.yfrne.2011.01.002

Brass, M., Schmitt, R. M., Spengler, S. \& Gergely, G. (2007) Investigating action understanding: Inferential processes versus action simulation. Current Biology 17(24):2117-21. http://dx.doi.org/10.1016/j.cub.2007.11.057

Brazelton, T. B. (1986) The development of newborn behavior. In: Human growth: A comprehensive treatise, eds. F. Faulkner \& J. M. Tanner (vol. 2, pp. 519-40). New York: Plenum Press.

Brennan, S. E. \& Clark, H. H. (1996) Conceptual pacts and lexical choice in conversation. Journal of Experimental Psychology: Learning, Memory, and Cognition 22(6):1482-93. 
http://dx.doi.org/10.1037/0278-7393.22.6.1482

Brennan, S. E. \& Hanna, J. E. (2009) Topics in Cognitive Science 1(2):274-91. http://dx.doi.org/10.1111/j.1756-8765.2009.01019.x

Bromberg-Martin, E. S., Hikosaka, O. \& Nakamura, K. (2010) Coding of task reward value in the Dorsal Raphne Nucleus. Journal of Neuroscience 30(18):6262-72. http://dx.doi.org/10.1523/JNEUROSCI.001510.2010

Brown, J., Aczel, B., Jimenez, L., Kaufman, S. B. \& Plaisted-Grant, K. (2010) Intact implicit learning in autism spectrum conditions. Quarterly Journal of Experimental Psychology 63(9):1789-1812. http://dx.doi.org/10.1080/17470210903536910

Broz, F., Nourbakhsh, I. \& Simmons, R. (in press). Planning for human-robot interaction in situated social tasks: The impact of representing time and intention. International Journal of Social Robotics.

Bruner, J. (1983) Child's Talk. New York: Norton.

Buck, R., Losow, J. I., Murphy, M. M. \& Constanzo, P. (1992) Social facilitation and inhibition of emotional expression and communication. Journal of Personality and Social Psychology 63(6):962-8. http://dx.doi.org/10.1037/0022-3514.63.6.962

Buckner, R. L. \& Carroll, D. C. (2007) Self-projection and the brain. Trends in Cognitive Sciences 11(2):49-57. http://dx.doi.org/10.1016/j.tics.2006.11.004

Burgess, P. W., Dumontheil, I. \& Gilbert, S. J. (2007) The gateway hypothesis of rostral prefrontal cortex (area 10) function. Trends in Cognitive Sciences 11(7):290-8. http://dx.doi.org/10.1016/j.tics.2007.05.004

Caggiano, V., Fogassi, L., Rizzolatti, G., Thier, P. \& Casile, A. (2009) Mirror neurons differentially encode the peripersonal and extrapersonal space of monkeys. Science 324(5925):403-6. http://dx.doi.org/10.1126/science.1166818

Camara, E., Rodriguez-Fornells, A. \& Munte, T. F. (2008) Functional connectivity of reward processing in the brain. Frontiers in Human Neuroscience 2:19. http://dx.doi.org/10.3389/neuro.09.019.2008

Carletta, J., Hill, R.L., Nicol, C., Taylor, T., de Ruiter J.P., Bard, E.G. (2010) Eyetracking for two-person tasks with manipulation of a virtual world. Behavior Research Methods 42(1):254-65. http://dx.doi.org/10.3758/BRM.42.1.254

Carpendale, J. E. M. \& Lewis, C. (2004) Constructing an understanding of mind: The development of children's social understanding within social interaction. Behavioral and Brain Sciences 27(1):79-150. http://dx.doi.org/10.1017/S0140525X04000032

Catani, M., Jones, D. K., Daly, E., Embiricos, N., Deeley, Q., Pugliese, L. et al. (2008) Altered cerebellar feedback projections in Asperger syndrome. NeuroImage 41(4):1184-91. http://dx.doi.org/10.1016/j.neuroimage.2008.03.041

Catmur, C., Gillmeister, H., Bird, G., Liepelt, R., Brass, M. \& Heyes, C. (2008) Through the looking glass: Counter-mirror activation following incompatible sensorimotor learning. European Journal of Neuroscience 28(6):1208-15. http://dx.doi.org/10.1111/j.1460-9568.2008.06419.x

Catmur, C., Walsh, V. \& Heyes, C. (2007) Sensorimotor learning configures the human mirror system. 
Current Biology 17(17):1527-31. http://dx.doi.org/10.1016/j.cub.2007.08.006

Chakrabarti, B. \& Baron-Cohen, S. (2011) Variation in the human Cannabinoid Receptor (CNR1) gene modulates gaze duration for happy faces. Molecular Autism 2(1):10. http://dx.doi.org/10.1186/2040-2392$2-10$

Chartrand, T. L. \& Bargh, J. A. (1999) The chameleon effect: The perception-behavior link and social interaction. Journal of Personality and Social Psychology 76(6):893-910. http://dx.doi.org/10.1037/00223514.76.6.893

Chen, F.S. \& Johnson, S.C. (in press) An oxytocin receptor gene variant predicts attachment anxiety in females and autism-spectrum traits in males. Social Psychological and Personality Science. http://dx.doi.org/10.1177/1948550611410325

Choi, V. S., Gray, H. M. \& Ambady, N. (2005) The glimpsed world: Unintended communication and unintended perception. In: The New Unconscious, eds. R. R. Hassin, J. S. Uleman, \& J. A. Bargh (pp. 30933). New York: Oxford University Press.

Chomsky, N. (1979) Language and Responsibility. Hassocks: Harvester Press.

Chura, L. R., Lombardo, M. V., Ashwin, E., Auyeung, B., Chakrabarti, B., Bullmore, E. T. et al. (2010) Organizational effects of fetal testosterone on human corpus callosum size and asymmetry. Psychoneuroendocrinology 35(1):122-32. http://dx.doi.org/10.1016/j.psyneuen.2009.09.009

Clark, H. H. (1996) Using Language. Cambridge: Cambridge University Press.

Cleeremans, A. (2008) Consciousness: the radical plasticity thesis. Progress in Brain Research 168:19-33. http://dx.doi.org/10.1016/S0079-6123(07)68003-0

Cleeremans, A. (2011) The radical plasticity thesis: how the brain learns to be conscious. Frontiers in Psychology 2:86. http://dx.doi.org/10.3389/fpsyg.2011.00086

Cleeremans, A., Timmermans, B. \& Pasquali, A. (2007) Consciousness and metarepresentation: A computational sketch. Neural Networks 20(9):1032-9. http://dx.doi.org/10.1016/j.neunet.2007.09.011

Coan, J. A. (2008) Toward a neuroscience of attachment. In: Handbook of Attachment: Theory, Research, and Clinical Applications, ed. J. Cassidy \& P. R. Shaver. (2nd edition, pp. 241-65). New York: Guilford Press.

Cohn, J. F. \& Tronick, E. Z. (1989) Specificity of infants' response to mothers' affective behavior. Journal of the American Academy of Child and Adolescent Psychiatry 28:242-8. http://dx.doi.org/10.1097/00004583-198903000-00016

Cooper, J.C., Dunne, S., Furey, T. \& O'Doherty, J. P. (in press) Human dorsal striatum encodes prediction errors during observational learning of instrumental actions. Journal of Cognitive Neuroscience. http://dx.doi.org/10.1162/jocn_a_00114

Corbetta M., Patel G. H. \& Shulman G. L. (2008) The reorienting system of the human brain: From environment to theory of mind. Neuron 58():306-24. http://dx.doi.org/10.1016/j.neuron.2008.04.017

Costall, A. (1995) Socializing affordances. Theory \& Psychology 5(4):467-81. http://dx.doi.org/10.1177/0959354395054001 
Costall, A. (2006) Introspectionism and the mythical origins of modern scientific psychology. Consciousness and Cognition 15(4):634-54. http://dx.doi.org/10.1016/j.concog.2006.09.008

Costall, A., Leudar, I. \& Reddy, V. (2006) Failing to see the irony in 'mind-reading'. Theory \& Psychology 16(2):163-7. http://dx.doi.org/10.1177/0959354306062533

Crespi, B. \& Badcock, C. (2008) Psychosis and autism as diametrical disorders of the social brain. Behavioral and Brain Sciences 31(3):241-61. http://dx.doi.org/10.1017/S0140525X08004214

Csibra, G. \& Gergely, G. (2009) Natural pedagogy. Trends in Cognitive Sciences 13(4):148-53. http://dx.doi.org/10.1016/j.tics.2009.01.005

Damasio, A. (2010) Self Comes to Mind. Pantheon.

Daunizeau, J., den Ouden, H. E., Pessiglione, M., Kiebel, S. J., Friston, K. J. \& Stephan, K. E. (2010b) Observing the observer (II): Deciding when to decide. PLoS ONE 5(12): 15555 . http://dx.doi.org/10.1371/journal.pone.0015555

Daunizeau, J., den Ouden, H. E., Pessiglione, M., Kiebel, S. J., Stephan, K. E. \& Friston, K. J. (2010a) Observing the observer (I): Meta-bayesian models of learning and decision-making. PLoS ONE 5(12):e15554. http://dx.doi.org/10.1371/journal.pone.0015554

De Jaegher, H., Di Paolo, E. (2007) Participatory sensemaking. An enactive approach to social cognition. Phenomenology and the Cognitive Sciences 6(4):485-507. 10.1007/s11097-007-9076-9

De Jaegher, H., Di Paolo, E. \& Gallagher, S. (2010) Can social interaction constitute social cognition? Trends in Cognitive Sciences 14(10):441-7. http://dx.doi.org/10.1016/j.tics.2010.06.009

de Lange, F. P., Spronk, M., Willems, R. M., Toni, I. \& Bekkering, H. (2008) Complementary systems for understanding action intentions. Current Biology 18(6):454-7. http://dx.doi.org/10.1016/j.cub.2008.02.057

Dewey, J. (1950) Reconstruction in Philosophy. New York: The new American library.

Dumas, G., Nadel, J., Soussignan, R., Martinerie, J. \& Garnero, L. (2010) Inter-brain synchronization during social interaction. PLOS ONE 5(8):e12166. http://dx.doi.org/10.1371/journal.pone.0012166

Farroni, T., Csibra, G., Johnson, M. \& Simion, F. (2002) Eye contact detection at birth. Proceedings of the National Academy of Sciences 99(14):9602-5. http://dx.doi.org/10.1073/pnas.152159999

Fiebich, A. \& Gallagher, S. (in press). Joint attention in joint action. Philosophical Psychology.

Fiske, S. T. \& Depret, E. (1996) Control, interdependence, and power: Understanding social cognition in its social context. European Review of Social Ps ychology 7(1):31-61. http://dx.doi.org/10.1080/14792779443000094

Fogel, A. (1993) Developing through Relationships: Origins of Communication, Self and Culture. New York: Harvester Weatsheaf.

Frijda, N. H. (1986) The Emotions. Cambridge University Press.

Friston, K. (2008) Hierarchical models in the brain. PLoS Computational Biology 4(11): e1000211. http://dx.doi.org/10.1371/journal.pcbi.1000211. 
Frith, C. D. \& Frith, U. (2006) The neural basis of mentalizing. Neuron 50(4):531-4. http://dx.doi.org/10.1016/j.neuron.2006.05.001

Frith, C. D. \& Frith, U. (2008) Implicit and explicit processes in social cognition. Neuron 60(3):503-10. http://dx.doi.org/10.1016/j.neuron.2008.10.032

Frith, U. \& Frith, C. D. (2010). The social brain: Allowing humans to boldly go where no other species has been. Philosophical Transactions of the Royal Society B: Biological Sciences 365(1537):165-76. http://dx.doi.org/10.1098/rstb.2009.0160

Froese, T. \& Di Paolo, E. A. (2010) Modeling social interaction as perceptual crossing: An investigation into the dynamics of the interaction process. Connection Science 22(1):43-68. http://dx.doi.org/10.1080/09540090903197928

Fuchs, T. (2009) Das Gehirn - ein Beziehungsorgan. Eine phänomenologisch-ökologische Konzeption. Stuttgart: Kohlhammer.

Fuchs, T. \& De Jaegher, H. (2009) Enactive intersubjectivity: Participatory sense-making and mutual incorporation. Phenomenology and the Cognitive Sciences, 8(4):465-86. http://dx.doi.org/10.1007/s11097009-9136-4

Gallagher, S. (2001) The practice of mind: Theory, simulation, or interaction? Journal of Consciousness Studies 8(5-7):83-108. http://pegasus.cc.ucf.edu/ gallaghr/practice01.htm

Gallagher, S. (2005) How the Body Shapes the Mind. Oxford: Oxford University Press.

Gallagher, S. (2007) Simulation trouble. Social Neuroscience 2(3-4):353-65. http://dx.doi.org/10.1080/17470910601183549

Gallagher, S. (2008) Direct perception in the intersubjective context. Consciousness and Cognition 17(2):535-43. http://dx.doi.org/10.1016/j.concog.2008.03.003

Gamer, M. \& Buchel, C. (2009) Amygdala activation predicts gaze toward fearful eyes. Journal of Neuroscience 29(28):9123-6. http://dx.doi.org/10.1523/JNEUROSCI.1883-09.2009

Gamer, M., Zurowski, B. \& Buchel, C. (2010) Different amygdala subregions mediate valence-related and attentional effects of oxytocin in humans. Proceedings of the National Academy of Sciences 107(20):9400-5. http://dx.doi.org/10.1073/pnas.1000985107

Gangopadhyay, N. \& Schilbach, L. (in press) Seeing minds: A neurophilosophical investigation of the role of perception-action coupling in social perception. Social Neuroscience. http://dx.doi.org/10.1080/17470919.2011.633754

Garner, W. R. (1999). Reductionism reduced: Review of 'Toward a new behaviorism: The case against perceptual reductionism' by William R. Uttal. Contemporary Psychology 44:20-1.

Garrod, S. \& Pickering, M.J. (2004) Why is conversation so easy? Trends in Cognitive Sciences 8(1):8-11. http://dx.doi.org/10.1016/j.tics.2003.10.016

Gergely, G. \& Watson, J. S. (1996) The social biofeedback theory of parental affect-mirroring: The development of emotional self-awareness and self-control in infancy. International Journal of Psychoanalysis 77(6):1181-212. http://www.pep-web.org/document.php?id=ijp.077.1181a 
Gibson, J. J. (1979) The Ecological Approach to Visual Perception. Boston: Houghton Mifflin.

Gilbert, S. J., Meuwese, J. D., Towgood, K. J., Frith, C. D. \& Burgess, P. W. (2009) Abnormal functional specialization within medial prefrontal cortex in high-functioning autism: A multi-voxel similarity analysis. Brain 132(4):869-78. http://dx.doi.org/10.1093/brain/awn365

Giles, H., Coupland, N. \& Coupland, J. (1992) Accommodation theory: Communication, context and consequences. In: Contexts of Accommodation, eds. H. Giles, J. Coupland, \& N. Coupland (pp. 1-68). Cambridge University Press.

Goldman, A. (2006) Simulating Minds. The Philosophy, Psychology, and Neuroscience of Mindreading. Oxford University Press.

Goldstein, M. H. \& Schwade, J. A. (2008). Social feedback to infants' babbling facilitates rapid phonological learning. Psychological Science 19(5):515-23. http://dx.doi.org/10.1111/j.14679280.2008.02117.x

Goldstein, M. H. \& Schwade, J. (2010) From birds to words: Perception of structure in social interactions guides vocal development and language learning. In: The Oxford Handbook of Developmental Behavioral Neuroscience, eds. M. S. Blumberg, J. H. Freeman \& S. R. Robinson (pp. 708-29). Oxford University Press.

Goldstein, M. H., Schwade, J., Briesch, J. \& Syal, S. (2009) Learning while babbling: Prelinguistic objectdirected vocalizations signal a readiness to learn. Infancy 15(4):362-91. http://dx.doi.org/10.1111/j.15327078.2009.00020.x

Goldstein, M. H., Waterfall, H. R., Lotem, A., Halpern, J.Y., Schwade, J.A., Onnis, L. \& Edelman, S. (2010) General cognitive principles for learning structure in time and space. Trends in Cognitive Sciences 14(6):249-58. http://dx.doi.org/10.1016/j.tics.2010.02.004

Groen, W. B., Tesink, C., Petersson, K. M., van Berkum, J., van der Gaag, R. J., Hagoort, P. \& Buitelaar, J. K. (2010) Semantic, factual, and social language comprehension in adolescents with autism: an FMRI study. Cerebral Cortex 20(8):1937-45. http://dx.doi.org/10.1093/cercor/bhp264

Grossmann, T. \& Johnson, M. H. (2010) Selective prefrontal cortex responses to joint attention in early infancy. Biology Letters 6(4):540-543. http://dx.doi.org/10.1098/rsbl.2009.1069

Grossman, T., Johnson, M., Farroni, T. \& Csibra, G. (2007) Social perception in the infant brain: Gamma oscillatory activity in response to eye gaze. Social Cognitive and Affective Neuroscience 2(4):284-91. http://dx.doi.org/10.1093/scan/nsm025

Haggard, P. (2009) The sources of human volition. Science 324(5928):731-3. doi10.1126/science.1173827.

Haggard, P. \& Tsakiris, M. (2009) The experience of agency: Feelings, judgments, and responsibility. Current Directions in Psychological Science 18(4):242-24. http://dx.doi.org/10.1111/j.14678721.2009.01644.x

Hampton, A. N., Bossaerts, P. \& O'Doherty, J. P. (2008) Neural correlates of mentalizing-related computations during strategic interactions in humans. Proceedings of the National Academy of Sciences 105(18):6741-6. http://dx.doi.org/10.1073/pnas.0711099105 
Harrist, A. W. \& Waugh, R. M. (2002) Dyadic synchrony: Its structure and function in children's development. Developmental Review 22(4):555-92. http://dx.doi.org/10.1016/S0273-2297(02)00500-2

Hasson U, Ghazanfar AA, Galantucci B, Garrod S, Keysers C (2012). Brain-to-brain coupling: a mechanism for creating and sharing a social world. Trends Cogn Sci. 16(2):114-21.

Heider, F. (1958). The Psychology of Interpersonal Relations. New York: John Wiley \& Sons.

Heider, F. \& Simmel, M. (1944) An experimental study of apparent behavior. The American Journal of Psychology 57(2):243-259. http://dx.doi.org/10.2307/1416950

Henckens, M. J., Hermans, E. J., Pu, Z., Joels, M. \& Fernandez, G. (2009) Stressed memories: how acute stress affects memory formation in humans. Journal of Neuroscience 29(32):10111-9. http://dx.doi.org/10.1523/JNEUROSCI.1184-09.2009

Hermans, E. J., Bos, P. A., Ossewaarde, L., Ramsey, N. F., Fernandez, G. \& van Honk, J. (2010) Effects of exogenous testosterone on the ventral striatal BOLD response during reward anticipation in healthy women. NeuroImage 52(1):277-83. http://dx.doi.org/10.1016/j.neuroimage.2010.04.019

Hertwig, R. \& Erev, I. (2009) The description-experience gap in risky choice. Trends in Cognitive Sciences 13(12):517-23. http://dx.doi.org/10.1016/j.tics.2009.09.004

Heyes, C. (2010) Where do mirror neurons come from? Neuroscience \& Biobehavioral Reviews 34(4):575-83. http://dx.doi.org/10.1016/j.neubiorev.2009.11.007

Heyes, C., Bird, G., Johnson, H. \& Haggard, P. (2005) Experience modulates automatic imitation. Cognitive Brain Research 22(2):233-40. http://dx.doi.org/10.1016/j.cogbrainres.2004.09.009

Hikosaka, O. \& Isoda, M. (2010) Switching from automatic to controlled behavior: Cortico-basal ganglia mechanisms. Trends in Cognitive Sciences 14(4):154-61. http://dx.doi.org/10.1016/j.tics.2010.01.006

Hobson, R. P. (1991) Against the theory of 'Theory of Mind'. British Journal of Developmental Psychology 9(1):33-51. http://dx.doi.org/0.1111/j.2044-835X.1991.tb00860.x

Hobson, R. P. (1999) Intersubjective foundations for joint attention: Co-ordinating attitudes (rather than actions). Paper presented at the Joint Attention Conference, 11-13 June, 1999, University of Warwick.

Hull, C. L. (1943) Principles of behavior. New York: Appleton-Century-Crofts.

Hutto, D. (2008) Folk-psychological narratives. The sociocultural basis of understanding reasons. Cambridge, Mass.: MIT Press.

Izuma, K., Saito, D. N. \& Sadato, N. (2008) Processing of social and monetary rewards in the human striatum. Neuron 58(2):284-94. http://dx.doi.org/10.1016/j.neuron.2008.03.020

Jaffe, J., Beebe, B., Feldstein, S., Crown, C. L. \& Jasnow, M. D. (2001) Rhythms of dialogue in infancy. Monographs of the Society for Research in Child Development 66(2, Serial No. 265).

Jenkins, J. J. (1986). Interview with James J. Jenkins. In: The Cognitive Revolution in Psychology, ed. B. J. Baars (pp. 239-52). New York: Guilford Press.

Jermann, P., Nüssli, M.-A. \& Li, W. (2010). Using dual eye-tracking to unveil coordination and expertise in collaborative Tetris. Proceedings of the 24th ACM BCS Conference on Human Computer Interaction, 
Dundee, UK, September 6-10, 2010.

Jones, E. E. \& Gerard, H. B. (1967) Foundations of Social Psychology. NY: John Wiley \& Sons.

Jones, E. E. \& Nisbett, R. E. (1971) The Actor and the Observer: Divergent Perceptions of the Causes of Behavior. New York: General Learning Press.

Kampe, K. K., Frith, C. D. \& Frith, U. (2003) "Hey John”: signals conveying communicative intention toward the self activate brain regions associated with "mentalizing," regardless of modality. Journal of Neuroscience 23(12):5258-63. http://www.jneurosci.org/content/23/12/5258.full.pdf

Karmiloff-Smith, A. (1992) Beyond Modularity: A Developmental Perspective on Cognitive Science. Cambridge: MIT Press.

Kelso, J. A. S., de Guzman, G. C., Reveley, C. \& Tognoli, E. (2009) Virtual Partner Interaction (VPI): exploring novel behaviors via coordination dynamics. PLoS ONE 4(6):e5749. http://dx.doi.org/10.1371/journal.pone.0005749

Keltner, D. \& Haidt, J. (1999) Social functions of emotions at four levels of analysis. Cognition and Emotion 13(5):505-21. http://dx.doi.org/10.1080/026999399379168

Kennedy, D. P., Redcay, E. \& Courchesne, E. (2006) Failing to deactivate: resting functional abnormalities in autism. Proceedings of the National Academy of Sciences 103(21):8275-80. http://dx.doi.org/10.1073/pnas.0600674103

Keysers, C. \& Gazzola, V. (2007) Integrating simulation and theory of mind: From self to social cognition. Trends in Cognitive Sciences 11(5):194-6. http://dx.doi.org/10.1016/j.tics.2007.02.002

Khan, M. A., Lawrence, G., Fourkas, A., Franks, I. M., Elliott, D. \& Pembroke, S. (2003) Online versus offline processing visual feedback in the control of movement amplitude. Acta Psychologica 113(1):8397. http://dx.doi.org/10.1016/S0001-6918(02)00156-7

King-Casas, B., Sharp, C., Lomax-Bream, L., Lohrenz, T., Fonagy, P. \& Montague, P. R. (2008) The rupture and repair of cooperation in borderline personality disorder. Science 321(5890):806-10. http://dx.doi.org/10.1126/science.1156902

King-Casas, B., Tomlin, D., Anen, C., Camerer, C. F., Quartz, S. R. \& Montague, P. R. (2005) Getting to know you: reputation and trust in a two-person economic exchange. Science 308(5718):78-83. http://dx.doi.org/10.1126/science.1108062

Klin, A., Jones, W., Schultz, R. \& Volkmar, F. (2003) The enactive mind, or from actions to cognition: Lessons from autism. Philosophical Transactions of the Royal Society London B: Biological Sciences 358(1430):345-60. http://dx.doi.org/10.1098/rstb.2002.1202

Klin, A., Lin, D. J., Gorrindo. P., Ramsay, G. \& Jones, W. (2009) Two-year-olds with autism orient to non-social contingencies rather than biological motion. Nature 459(7244):257-61. http://dx.doi.org/10.1038/nature07868

Knoblich, G. \& Sebanz, N. (2008) Evolving intentions for social interaction: from entrainment to joint action. Philosophical Transactions of the Royal Society London B: Biological Sciences 363(1499):202131. http://dx.doi.org/10.1098/rstb.2008.0006 
Kokal, I., Gazzola, V. \& Keysers, C. (2009) Acting together in and beyond the mirror neuron system. NeuroImage 47(4):2046-56. http://dx.doi.org/10.1016/j.neuroimage.2009.06.010

Konvalinka, I., Vuust, P., Roepstroff, A. \& Frith, C. D. (2010) Follow you, follow me: Continuous mutual prediction and adaptation in joint tapping. The Quarterly Journal of Experimental Psychology 63(11):2220-30. http://dx.doi.org/10.1080/17470218.2010.497843

Kourtis, D., Sebanz, N. \& Knoblich, G. (2010) Favouritism in the motor system: Social interaction modulates action simulation. Biology Letters 6(6):758-61. http://dx.doi.org/10.1098/rsbl.2010.0478

Krueger, J. (2010) Extended cognition and the space of social interaction. Consciousness and Cognition 20(3):643-57. http://dx.doi.org/10.1016/j.concog.2010.09.022

Kugiumutzakis, G. (1998) Neonatal imitation in the intersubjective companion space. In: Intersubjective Communication and Emotion in Early Ontogeny, ed. S. Braten (pp. 63-88). Cambridge: Cambridge University Press.

Kuhl, P. K. (2007a) Cracking the speech code: How infants learn language. Acoustical Science and Technology 28(2):71-83. http://dx.doi.org/10.1250/ast.28.71

Kuhl, P. K. (2007b) Is speech learning "gated" by the social brain? Developmental Science 10(1):110-20. http://dx.doi.org/10.1111/j.1467-7687.2007.00572.x

Kuhl, P. K., Tsao, F. M. \& Liu, H. M. (2003) Foreign-language experience in infancy: Effects of shortterm exposure and social interaction on phonetic learning. Proceedings of the National Academy of Sciences 100:(15)9096-101. http://dx.doi.org/10.1073/pnas.1532872100

Kuzmanovic, B., Schilbach, L., Lehnhardt, F. G., Bente, G. \& Vogeley, K. (2011) A matter of words: Impact of verbal and nonverbal information on impression formation in high-functioning autism. Research in Autism Spectrum Disorders 5(1):604-13. http://dx.doi.org/10.1016/j.rasd.2010.07.005

Lavelli, M. \& Fogel, A. (2002) Developmental changes in mother-infant face-to-face communication: Birth to 3 months. Developmental Psychology 38(2):288-305. http://dx.doi.org/10.1037/00121649.38.2.288

Leahey, T. H. (1992) The mythical revolutions of American psychology. American Psychologist 47(2):308-18. http://dx.doi.org/10.1037//0003-066X.47.2.308

Leekam, S. \& Ramsden, C. (2006) Dyadic orienting and joint attention in preschool children with autism. Journal of Autism and Developmental Disorders 36(2):185-97. http://dx.doi.org/10.1007/s10803-0050054-1

Legerstee, M. \& Varghese, J. (2001) The role of maternal affect mirroring on social expectancies in threemonth-old infants. Child Development 72(5):1301-13. http://dx.doi.org/10.1111/1467-8624.00349

Lenay, C., Stewart, J., Rohde, M., Ali Amar, A. (2011) "You never fail to surprise me": The hallmark of the Other: Experimental study and simulations of perceptual crossing. Interaction Studies 12(3):373-96. http://dx.doi.org/10.1075/is.12.3.01len

Leudar, I. \& Costall, A. (2008) Against theory of mind. London: Macmillan.

Marcus, G. F., Vijayan, S., Rao, S. B. \& Vishton, P. M. (1999) Rule learning by seven-month-old infants. 
Science 283(5398):77-80. http://dx.doi.org/10.1126/science.283.5398.77

Marsh, K. L., Richardson, M. J. \& Schmidt, R. C. (2009) Social connection through joint action and interpersonal coordination. Topics in Cognitive Science 1:320-39. http://dx.doi.org/10.1111/j.17568765.2009.01022.x

Materna, S., Dicke, P. W. \& Thier, P. (2008) Dissociable roles of the superior temporal sulcus and the intraparietal sulcus in joint attention: a functional magnetic resonance imaging study. Journal of Cognitive Neuroscience 20(1):108-19. http://dx.doi.org/10.1162/jocn.2008.20.1.108

McQuaid, N., Bibok, J. \& Carpendale, J. (2009) Relation between maternal contingent responsiveness and infant social expectations. Infancy 14(3):390-401. http://dx.doi.org/10.1080/15250000902839!955

Meltzoff, A. \& Moore, K. (1977) Imitation of facial and manual gestures by human neonates. Science 198(4312):75-8. http://dx.doi.org/10.1126/science.198.4312.75

Mitchell, J. P. (2009) Social psychology as a natural kind. Trends in Cognitive Sciences 13(6):246-51. http://dx.doi.org/10.1016/j.tics.2009.03.008

Mojzisch, A., Schilbach, L., Helmert, J. R., Pannasch, S., Velichkovsky, B. M. \& Vogeley, K. (2006) The effects of self-involvement on attention, arousal, and facial expression during social interaction with virtual others: A psychophysiological study. Social Neuroscience 1(3-4):184-95. http://dx.doi.org/10.1080/17470910600985621

Moll, H., Carpenter, M. \& Tomasello, M. (2007) Fourteen-month-olds know what others experience only in joint engagement. Developmental Science 10(6):826-835. http://dx.doi.org/10.1111/j.14677687.2007.00615.x

Montague, P. R., Berns, G. S., Cohen, J. D., McClure, S. M., Pagnoni, G., Dhamala, M., Wiest, M. C., Karpov, I., King, R. D., Apple, N. \& Fischer, R. E. (2002) Hyperscanning: Simultaneous fMRI during linked social interactions. NeuroImage 16(4):1159-64. http://dx.doi.org/10.1006/nimg.2002.1150

Mundy, P. \& Newell, L. (2007) Attention, joint attention, and social cognition. Current Directions in Psychological Science 16(5):269-74. http://dx.doi.org/10.1111/j.1467-8721.2007.00518.x

Murray, L. \& Trevarthen, C. (1985). Emotional regulation of interactions between two-month-old infants and their mothers. In: Social Perception in Infancy, eds. T. Field \& N. Fox (pp. 177-97). Norwood, NJ: Ablex.

Muscatell, K. A., Addis, D. R. \& Kensinger, E. A. (2010) Self-involvement modulates the effective connectivity of the autobiographical memory network. Social Cognitive and Affective Neuroscience 5(1):68-76. http://dx.doi.org/10.1093/scan/nsp043

N'Diaye, K., Sander, D. \& Vuilleumier, P. (2009) Self-relevance processing in the human amygdala: Gaze direction, facial expression, and emotion intensity. Emotion 9(6):798-806. http://dx.doi.org/10.1037/a0017845

Nadel, J. \& Tremblay-Leveau, H. (1999) Early perception of social contingencies and interpersonal intentionality: Dyadic and triadic paradigms. In: Early Social Cognition, ed. P. Rochat (pp. 189-212). Mahwah, NJ: Erlbaum.

Nadig, A., Vivanti, G. \& Ozonoff, S. (2009) Adaptation of object descriptions to a partner under 
increasing communicative demands: A comparison of children with and without autism. Autism Research 2(6):334-347. http://dx.doi.org/10.1002/aur.102

Nagy, E. \& Molnar, P. (2004) Homo imitans or homo provocans? Human imprinting model of neonatal imitation. Infant Behavior and Development 27(1):54-63. http://dx.doi.org/10.1016/j.infbeh.2003.06.004

Neisser, U. (1980) On "Social Knowing". Personality and Social Psychology Bulletin 6(4):601-5. http://dx.doi.org/10.1177/014616728064012

Neisser, U. (1997). The future of cognitive science: An ecological analysis. In: The Future of the Cognitive Revolution, eds. D. M. Johnson \& C. E. Erneling (pp. 247-60). New York: Oxford University Press.

Newen, A. \& Schlicht, T. (2009) Understanding other minds: A criticism of Goldman's Simulation Theory and an outline of the Person Model Theory. Grazer Philosophische Studien 79(1):209-42.

Newman-Norlund, R. D., Bosga, J., Meulenbroek, R. G. \& Bekkering, H. (2008) Anatomical substrates of cooperative joint-action in a continuous motor task: Virtual lifting and balancing. NeuroImage 41(1):16977. http://dx.doi.org/10.1016/j.neuroimage.2008.02.026

Newman-Norlund, R. D., van Schie, H. T., van Zuijlen, A. M. J. \& Bekkering, H. (2007) The mirror neuron system is more active during complementary compared with imitative action. Nature Neuroscience 10(7):817-8. http://dx.doi.org/10.1038/nn1911

Niedenthal, P. M., Mermillod, M., Maringer, M. \& Hess, U. (2010) The Simulation of Smiles (SIMS) model: Embodied simulation and the meaning of facial expression. Behavioral and Brain Sciences 33(6):417-33. http://dx.doi.org/10.1017/S0140525X10000865

Noë, A. (2009). Out of Our Heads. Hill \& Wang.

Northoff, G. \& Bermpohl, F. (2004) Cortical midline structures and the self. Trends in Cognitive Sciences 8(3):102-7. http://dx.doi.org/10.1016/j.tics.2004.01.004

Oberman, L. M., Pineda, J. A. \& Ramachandran, V. S. (2007) The human mirror neuron system: a link between action observation and social skills. Social Cognitive and Affective Neuroscience 2(1):62-6. http://dx.doi.org/10.1093/scan/ns1022

Ochsner, K. N. \& Lieberman, M. D. (2001) The emergence of social cognitive neuroscience. American Psychologist 56(9):717-34. http://dx.doi.org/10.1037/0003-066X.56.9.717

Oullier, O. \& Basso, F. (2010) Embodied economics: How bodily information shapes the social coordination dynamics of decision-making. Philosophical Transactions of the Royal Society B: Biological Sciences 365(1538):291-301. http://dx.doi.org/10.1098/rstb.2009.0168

Over, H. \& Carpenter, M. (2009). Priming third-party ostracism increases affiliative imitation in children. Developmental Science 12(3):F1-8. http://dx.doi.org/10.1111/j.1467-7687.2008.00820.x

Pacherie, E. (2008) The phenomenology of action: A conceptual framework. Cognition 107(1):179-217. http://dx.doi.org/10.1016/j.cognition.2007.09.003

Panksepp, J., Herman, B. H., Vilberg, T., Bishop, P. \& DeEskinazi, F. G. (1980) Endogenous opioids and social behavior. Neuroscience \& Biobehavioral Reviews 4(4):473-87. http://dx.doi.org/10.1016/0149- 
Parise, E., Palumbo, L., Handl, A. \& Frederici, A. (2008). Gaze direction influences word processing in 4to 5-month-old infants: An ERP investigation. Poster presented at the Developmental Section Conference of the British Psychological Society, 1-3 September, Oxford.

Pasley, B.N., Mayes, L.C. \& Schultz, R.T. (2004) Subcortical discrimination of unperceived objects during binocular rivalry. Neuron 42, 163-172.

Pelphrey, K. A., Singerman, J. D., Allison, T. \& McCarthy, G. (2003) Brain activation evoked by perception of gaze shifts: the influence of context. Neuropsychologia 41(2):156-170. http://dx.doi.org/10.1016/S0028-3932(02)00146-X

Penn, D. C. and Povinelli, D. J. (2008) On the lack of evidence that non-human animals possess anything remotely resembling a 'theory of mind'. In: Social Intelligence: From Brain to Culture, eds. N. Emery, N. Clayton and C. Frith (pp. 415-30). Oxford: Oxford University Press.

Pessoa, L. \& Engelmann, J. B. (2010) Embedding reward signals into perception and cognition. Frontiers in Neuroscience 4:17. http://dx.doi.org/10.3389/fnins.2010.00017

Pexman, P. M., Rostad, K. R., McMorris, C. A., Climie, E. A., Stowkowy, J. \& Glenwright, M. R. (2011) Processing of ironic language in children with High-Functioning Autism Spectrum Disorder. Journal of Autism and Developmental Disorders 41(8):1097-112. http://dx.doi.org/10.1007/s10803-010-1131-7

Pfeiffer, U., Timmermans, B., Bente, G., Vogeley, K. \& Schilbach, L. (in press). The Non-Verbal Turing Test: Differentiating mind from machine in gaze-based social interaction. PLoS ONE. http://dx.doi.org/10.1371/journal.pone.0027591

Pickering, M. J. \& Garrod, S. (2004). Toward a mechanistic psychology of dialogue. Behavioral and Brain Sciences 27(2):169-90. Toward a mechanistic psychology of dialogue

Pierrot-Deseilligny, C., Milea, D. \& Muri, R. M. (2004) Eye movement control by the cerebral cortex. Current Opinion in Neurology 17(1):17-25. http://dx.doi.org/10.1097/00019052-200402000-00005

Pisella, L., Gréa, H., Tilikete, C., Vighetto, A., Desmurget, M., Rode, G., Boisson, D. \& Rossetti, Y. (2000) An 'automatic pilot' for the hand in human posterior parietal cortex: toward reinterpreting optic ataxia. Nature Neuroscience 3(7):729-36. http://dx.doi.org/10.1038/76694

Port, R. F. \& van Gelder, T. (1995) Mind as Motion: Explorations in the Dynamics of Cognition. MIT Press.

Press, C., Gillmeister, H. \& Heyes, C. (2007) Sensorimotor experience enhances automatic imitation of robotic action. Proceedings of the Royal Society B: Biological Sciences 274(1625):2509-14. http://dx.doi.org/10.1098/rspb.2007.0774

Preston, S. D. \& de Waal, F. B. (2002) Empathy: Its ultimate and proximate bases. Behavioral and Brain Sciences 25(1):1-20 http://dx.doi.org/10.1017/S0140525X02000018.

Prinz, J. (2003) Emotions embodied. In: R. Solomon (ed.), Thinking about Feeling. New York: Oxford University Press.

Raichle, M. E., MacLeod, A. M., Snyder, A. Z., Powers, W. J., Gusnard, D. A. \& Shulman, G. L. (2001) 
A default mode of brain function. Proceedings of the National Academy of Sciences 98(2):676-82. http://dx.doi.org/10.1073/pnas.98.2.676

Redcay, E., Dodell-Feder, D., Pearrow, M. J., Mavros, P. L., Kleiner, M., Gabrieli, J. D. \& Saxe, R. (2010) Live face-to-face interaction during fMRI: A new tool for social cognitive neuroscience. NeuroImage 50(4):1639-47. http://dx.doi.org/10.1016/j.neuroimage.2010.01.052

Reddy, V. (1996) Omitting the second-person in social understanding. Behavioral and Brain Sciences 19(1):140-1. http://dx.doi.org/10.1017/S0140525X00041996

Reddy, V. (2000) Coyness in early infancy. Developmental Science 3(2):186-92. http://dx.doi.org/10.1111/1467-7687.00112

Reddy, V. (2003) On being the object of attention: Implications for self-other consciousness. Trends in Cognitive Sciences 7(9):397-402. http://dx.doi.org/10.1016/S1364-6613(03)00191-8

Reddy, V. (2005) Before the "third element": Understanding attention to self. In: Joint Attention: Communication and Other Minds, eds. N. Eilan, C. Hoerl, T. McCormack, \& J. Roessler (pp. 85-109). Oxford: Clarendon Press.

Reddy, V. (2008) How Infants Know Minds. Cambridge: Harvard University Press.

Reddy, V. (in press) A gaze at grips with me. In: Joint Attention: New Developments in Psychology, Philosophy of Mind, and Social Neuroscience, ed. A. Seemann. MIT Press.

Reddy, V., Williams, E., Costantini, C. \& Lang, B. (2010) Engaging with the self: Mirror behaviour in autism, Down syndrome and typical development. Autism 14(5):531-46. http://dx.doi.org/10.1177/1362361310370397

Reid, V. M., Striano, T., Kaufman, J. \& Johnson, M. H. (2004). Eye gaze cueing facilitates neural processing of objects in 4-month-old infants. Neuroreport 15(16):2553-5. http://dx.doi.org/10.1097/00001756-200411150-00025

Richardson, D. C., Dale, R. \& Kirkham, N. Z. (2007) The art of conversation is coordination: common ground and the coupling of eye movements during dialogue. Psychological Science 18(5):407-13. http://dx.doi.org/10.1111/j.1467-9280.2007.01914.x

Richardson, M. J., Marsh, K. L. \& Baron, R. M. (2007) Judging and actualizing intrapersonal and interpersonal affordances. Journal of Experimental Psychology: Human Perception and Performance 33(4):845-59. http://dx.doi.org/10.1037/0096-1523.33.4.845

Rietveld, E. (2008) Situated normativity: The normative aspect of embodied cognition in unreflective action. Mind 117(468):973-1001. http://dx.doi.org/10.1093/mind/fzn050

Rizzolatti, G. \& Sinigaglia, C. (2010) The functional role of the parieto-frontal mirror circuit: Interpretations and misinterpretations. Nature Reviews Neuroscience 11(4):264-74. http://dx.doi.org/10.1038/nrn2805

Rochat, P. \& Striano, T. (2002) Who's in the mirror? Self-other discrimination in specular images by fourand nine-month-old infants. Child Development 73(1):35-46. http://dx.doi.org/10.1111/1467-8624.00390

Rossetti, Y., Pisella, L. \& Vighetto, A. (2003) Optic ataxia revisited: Visually guided action versus immediate visuomotor control. Experimental Brain Research. 153(2):171-9. 
http://dx.doi.org/10.1007/s00221-003-1590-6

Runeson, S. \& Frykholm, G. (1983) Kinematic specification of dynamics as an informational basis for person-and-action perception. Journal of Experimental Psychology: General 112(4):585-615. http://dx.doi.org/10.1037/0096-3445.112.4.585

Saffran, J. R., Newport, E. L., Aslin, R. N., Tunick, R. A. \& Barrueco, S. (1997). Incidental language learning: Listening (and learning) out of the corner of your ear. Psychological Science 8(2):101-5. 10.1111/j.1467-9280.1997.tb00690.x

Saito, D. N., Tanabe, H. C., Izuma, K., Hayashi, M. J., Morito, Y., Komeda, H. et al. (2010) "Stay tuned”: Inter-individual neural synchronization during mutual gaze and joint attention. Frontiers in Integrative Neuroscience 4:127. http://dx.doi.org/10.3389/fnint.2010.00127

Santos, N. S., Kuzmanovic, B., David, N., Rotarska-Jagiela, A., Eickhoff, S. B., Shah, J. N., Fink, G. R., Bente, G. \& Vogeley, K. (2010) Animated brain: A functional neuroimaging study on animacy experience. NeuroImage 53(1):291-302. http://dx.doi.org/10.1016/j.neuroimage.2010.05.080

Sarrazin, J.-C., Cleeremans, A. \& Haggard, P. (2008) How do we know what we are doing? Time, intention, and awareness of action. Consciousness and Cognition 17(3):602-15. http://dx.doi.org/10.1016/j.concog.2007.03.007

Sartori, L., Becchio, C., Bulgheroni, M. \& Castiello, U. (2009) Modulation of the action control system by social intention: Unexpected social requests override preplanned action. Journal of Experimental Psychology: Human Perception and Performance 35(5):1490-1500. http://dx.doi.org/10.1037/a0015777

Sato, A. \& Yasuda, A. (2005) Illusion of sense of self-agency: discrepancy between the predicted and actual sensory consequences of actions modulates the sense of self-agency, but not the sense of selfownership. Cognition 94(3):241-55. 10.1016/j.cognition.2004.04.003

Schilbach, L. (2010) A second-person approach to other minds. Nature Reviews Neuroscience 11(6):449.

Schilbach, L., Bzdok, D., Timmermans, B., Fox, P.T., Laird, A.R., Vogeley, K., Eickhoff, S.B. (in press). Minds at rest revisited: Using ALE meta-analyses to investigate commonalities in the neural correlates of socio-emotional processing and unconstrained cognition. PLoS One.

Schilbach, L., Eickhoff, S. B., Cieslik, E. C., Kuzmanovic, B. \& Vogeley, K. (in press) Shall we do this together? Social gaze influences action control in a comparison group, but not in individuals with highfunctioning autism. Autism. http://dx.doi.org/10.1177/1362361311409258

Schilbach, L., Eickhoff, S. B., Cieslik, E., Shah, N. J., Fink, G. R. \& Vogeley, K. (2010b) Eyes on me: an fMRI study of the effects of social gaze on action control. Social Cognitive and Affective Neuroscience 6(4):393-403. http://dx.doi.org/10.1093/scan/nsq067

Schilbach, L., Eickhoff, S. B., Mojzisch, A. \& Vogeley, K. (2008a) What's in a smile? Neural correlates of facial embodiment during social interaction. Social Neuroscience 3(1):37-50. http://dx.doi.org/10.1080/17470910701563228

Schilbach, L., Eickhoff, S. B., Rotarska-Jagiela, A., Fink, G. R. \& Vogeley, K. (2008b) Minds at rest? Social cognition as the default mode of cognizing and its putative relationship to the "default system" of the brain. Consciousness and Cognition 17(2):457-67. http://dx.doi.org/10.1016/j.concog.2008.03.013 
Schilbach, L., Wilms, M., Eickhoff, S. B., Romanzetti, S., Tepest, R., Bente, G., Shah, N. J., Fink, G. R. \& Vogeley, K. (2010a) Minds made for sharing: Initiating joint attention recruits reward-related neurocircuitry. Journal of Cognitive Neuroscience 22(12):2702-15. http://dx.doi.org/10.1162/jocn.2009.21401

Schilbach, L., Wohlschlaeger, A. M., Kraemer, N. C., Newen, A., Shah, N. J., Fink, G. R. \& Vogeley, K. (2006) Being with virtual others: Neural correlates of social interaction. Neuropsychologia 44(5):718-30. http://dx.doi.org/10.1016/j.neuropsychologia.2005.07.017

Schippers, M. B. \& Keysers, C. (2011) Mapping the flow of information within the putative mirror neuron system during gesture observation. http://dx.doi.org/10.1016/j.neuroimage.2011.02.018

Schippers, M. B., Roebroeck, A., Renken, R., Nanetti, L. \& Keysers, C. (2010) Mapping the information flow from one brain to another during gestural communication. Proceedings of the National Academy of Sciences 107(20):9388-93. http://dx.doi.org/10.1073/pnas.1001791107

Schmidt, R. C., Carello, C. \& Turvey, M. T. (1990) Phase transitions and critical fluctuations in the visual coordination of rhythmic movements between people. Journal of Experimental Psychology: Human Perception and Performance 16(2):227-47. http://dx.doi.org/10.1037/0096-1523.16.2.227

Schnell, K., Bluschke, S., Konradt, B. \& Walter, H. (2011) Functional relations of empathy and mentalizing: an fMRI study on the neural basis of cognitive empathy. NeuroImage 54(2):1743-54. http://dx.doi.org/10.1016/j.neuroimage.2010.08.024

Schonberg, T., Fox, C. R. \& Poldrack, R. A. (2011) Mind the gap: bridging economic and naturalistic risk-taking with cognitive neuroscience. Trends in Cognitive Sciences 15(1):11-9. http://dx.doi.org/10.1016/j.tics.2010.10.002

Schultz, R.T. (2005) Developmental deficits in social perception in autism: the role of the amygdala and fusiform face area. International Journal of Developmental Neuroscience, 23, 125.

Schutz, A. (1972) The Phenomenology of the Social World (G. Walsh \& F. Lehnert trans.). London: Heinemann Educational Books.

Sebanz, N., Bekkering, H. \& Knoblich, G. (2006) Joint action: Bodies and minds moving together. Trends in Cognitive Sciences 10(2):70-6. http://dx.doi.org/10.1016/j.tics.2005.12.009

Sebanz, N., Knoblich, G., Stumpf, L. \& Prinz, W. (2005) Far from action-blind: Representation of others' actions in individuals with autism. Cognitive Neuropsychology 22(3-4):433-54. http://dx.doi.org/10.1080/02643290442000121

Senju, A., Southgate, V., White, S. \& Frith, U. (2009) Mindblind eyes: An absence of spontaneous theory of mind in Asperger syndrome. Science 325(5942):883-5. http://dx.doi.org/10.1126/science.1176170

Shockley, K., Santana, M. V. \& Fowler, C. A. (2003) Mutual interpersonal postural constraints are involved in cooperative conversation. Journal of Experimental Psychology: Human Perception and Performance 29(2):326-32. http://dx.doi.org/10.1037/0096-1523.29.2.326

Short, J., Williams, E. \& Christie, B (1976) The Social Psychology of Telecommunications. New York: Wiley. 
Southgate, V. \& Hamilton, A. F. de C. (2008) Unbroken mirrors: Challenging a theory of autism. Trends in Cognitive Sciences 12(6):225-9. http://dx.doi.org/10.1016/j.tics.2008.03.005

Sporns, O., Chialvo, D. R., Kaiser, M. \& Hilgetag, C. C. (2004) Organization, development and function of complex brain networks. Trends in Cognitive Sciences 8(9):418-25. http://dx.doi.org/10.1016/j.tics.2004.07.008

Stel, M., van Dijk, E. \& Olivier, E. (2009) You want to know the truth? Then don't mimic! Psychological Science 20(6):693-9. http://dx.doi.org/10.1111/j.1467-9280.2009.02350.x

Stern, D. (1985) The Interpersonal World of the Infant. New York: Basic Books.

Striano, T., Kopp, C., Grossman, T. \& Reid, V. (2006) Eye contact influences neural processing of emotional expressions in 4-month-old infants. Social Cognitive and Affective Neuroscience 1(2):87-94. http://dx.doi.org/10.1093/scan/ns1008

Suda, M., Takei, Y., Aoyama, Y., Narita, K., Sato, T., Fukuda, M. \& Mikuni, M. (2010) Frontopolar activation during face-to-face conversation: An in situ study using near-infrared spectroscopy. Neuropsychologia 48(2):441-7. http://dx.doi.org/10.1016/j.neuropsychologia.2009.09.036

Suda, M., Takei, Y., Aoyama, Y., Narita, K., Sakurai, N., Fukuda, M. \& Mikuni, M. (2011) Autistic traits and brain activation during face-to-face conversations in typically developed adults. PLoS ONE 6(5):e20021. http://dx.doi.org/10.1371/journal.pone.0020021

Tamietto, M. \& de Gelder, B. (2010) Neural bases of the non-conscious perception of emotional signals. Nature Reviews Neuroscience 11(10):697-709. http://dx.doi.org/10.1038/nrn2889

Teufel, C., Fletcher, P. C. \& Davis, G. (2010) Seeing other minds: Attributed mental states influence perception. Trends in Cognitive Sciences 14(8):376-382. http://dx.doi.org/10.1016/j.tics.2010.05.005

Thelen, E. \& Smith, L. (1994) A Dynamic Systems Approach to the Development of Cognition and Action. MIT Press.

Thinès, G., Costall, A. \& Butterworth, G.E. (1991) Michotte's Experimental Phenomenology of Perception. Hillsdale, NJ: Erlbaum.

Thompson, E. (2007) Mind in Life. Biology, Phenomenology and the Sciences of the Mind. Harvard University Press.

Tognoli, E., Lagarde, J., DeGuzman, G. C. \& Kelso, J. A. (2007) The phi complex as a neuromarker of human social coordination. Proceedings of the National Academy of Sciences 104(19):8190-5. http://dx.doi.org/10.1073/pnas.0611453104

Tomasello, M. (1995). Joint attention as social cognition. In: Joint Attention: Its Origins and Role in Development, eds. C. Moore \& P. Dunham (pp. 103-30). Lawrence Erlbaum.

Tomasello, M. (2009) Why We Cooperate. MIT Press.

Tomasello, M. \& Carpenter, M. (2007) Shared intentionality. Developmental Science 10(1):121-5. http://dx.doi.org/10.1111/j.1467-7687.2007.00573.x

Tost, H., Braus, D. F., Hakimi, S., Ruf, M., Vollmert, C., Hohn, F. \& Meyer-Lindenberg, A. (2010) Acute D2 receptor blockade induces rapid, reversible remodeling in human cortical-striatal circuits. Nature 
Neuroscience 13(8):920-2. http://dx.doi.org/10.1038/nn.2572

Trevarthen, C. (1977) Descriptive analyses of infant communication behavior. In: Studies in MotherInfant Interaction: The Loch Lomond Symposium, ed. H.R. Schaffer (pp. 227-70). London: Academic Press.

Trevarthen, C. (1980) The foundations of intersubjectivity: Development of interpersonal and cooperative understanding in infants. In: The Social Foundations of Language and Thought: Essays in Honor of J. S. Bruner, ed. D. Olson (pp. 316-42). New York: Norton.

Triesch, J., Jasso, H. \& Deak, G. O. (2007) Emergence of mirror neurons in a model of gaze following. Adaptive Behavior 15(2):149-65. http://dx.doi.org/10.1177/1059712307078654

Triesch, J., Teuscher, C., Deak, G. O. \& Carlson, E. (2006) Gaze following: Why (not) learn it? Developmental Science 9(2):125-47. http://dx.doi.org/10.1111/j.1467-7687.2006.00470.x

Triplett, N. (1898) The dynamogenic factors in pacemaking and competition. The American Journal of Psychology 9(4):507-33. http://dx.doi.org/10.2307/1412188

Tylén, K., Weed, E., Wallentin, M., Roepstorff, A. \& Frith, C. (2010). Language as a tool for interacting minds. Mind \& Language 25(1):3-29. http://dx.doi.org/10.1111/j.1468-0017.2009.01379.x

Uddin, L. Q., Iacoboni, M., Lange, C. \& Keenan, J. P. (2007) The self and social cognition: the role of cortical midline structures and mirror neurons. Trends in Cognitive Sciences 11(4): 153-7. http://dx.doi.org/10.1016/j.tics.2007.01.001

Van Baaren, R. B., Holland, R. W., Kawakami, K. \& van Knippenberg, A. (2004) Mimicry and pro-social behavior. Psychological Science 15(1):71-7. http://dx.doi.org/10.1111/j.0963-7214.2004.01501012.x

Van Baaren, R. B., Maddux, W. W., Chartrand, T. L., De Bouter, C. \& Van Knippenberg, A. (2003) It takes two to mimic: Behavioral consequences of self-construals. Journal of Personality and Social Psychology 84(5):1093-102. http://dx.doi.org/10.1037/0022-3514.84.5.1093

Vogeley, K. \& Bente, G. (2010) “Artificial humans": Psychology and neuroscience perspectives on embodiment and nonverbal communication. Neural Networks 23(8-9):1077-90. http://dx.doi.org/10.1016/j.neunet.2010.06.003

Vogeley, K. \& Newen, A. (2009). Consciousness of oneself and others in relation to mental disorders. In: The Neuropsychology of Mental Illness, eds. S. Wood, N. Allen, C. Pantelis (pp. 408-13). Cambridge University http://ebooks.cambridge.org/chapter.jsf?bid=CBO9780511642197\&cid=CBO9780511642197A042

Volman, I., Toni, I., Verhagen, L. \& Roelofs, K. (2011) Endogenous testosterone modulates prefrontalamygdala connectivity during social emotional behavior. Cerebral Cortex 21(10):2282-. http://dx.doi.org/10.1093/cercor/bhr001

Wang, Y., Ramsey, R. \& Hamilton, A. (2011) The control of mimicry by eye contact is mediated by medial prefrontal cortex. Journal of Neuroscience 31(33):12001-10. http://dx.doi.org/10.1523/JNEUROSCI.0845-11.2011

Westermann, G, Mareschal, D, Johnson, MH, Sirois, S, Spratling, M, \& Thomas, M (2007) Neuroconstructivism. Developmental Science 10(1):75-83. http://dx.doi.org/10.1111/j.1467- 
Wheatley, T., Milleville, S. C. \& Martin, A. (2007) Understanding animate agents: Distinct roles for the social network and mirror system. Psychological Science 18(6):469-74. http://dx.doi.org/10.1111/j.14679280.2007.01923.x

Williams, J. H., Waiter, G. D., Perra, O., Perrett, D. I. \& Whiten, A. (2005) An fMRI study of joint attention experience. NeuroImage 25(1):133-40. http://dx.doi.org/10.1016/j.neuroimage.2004.10.047

Wilms, M., Schilbach, L., Pfeiffer, U., Bente, G., Fink, G. R. \& Vogeley, K. (2010). It's in your eyes-using gaze-contingent stimuli to create truly interactive paradigms for social cognitive and affective neuroscience. Social Cognitive and Affective Neuroscience 5(1):98-107. http://dx.doi.org/10.1093/scan/nsq024

Wolff, P. (1987). The Development of Behavioral States and the Expression of the Emotions in Early Infancy. Chicago: University of Chicago Press.

Worringham, C. J. \& Messick, D. M. (1983) Social facilitation of running: An unobtrusive study. The Journal of Social Psychology 121(1):23-9. http://dx.doi.org/10.1080/00224545.1983.9924462

Yoshida, W., Dolan, R. J. \& Friston, K. J. (2008) Game theory of mind. PLoS Computational Biology 4(12):e1000254. http://dx.doi.org/10.1371/journal.pcbi.1000254

Zahavi, D. (2005) Subjectivity and Selfhood: Investigating the First-Person Perspective. Cambridge, MA: The MIT Press.

Zahavi, D. \& Parnas, J. (2003) Conceptual problems in infantile autism research: Why cognitive science needs phenomenology. Journal of Consciousness Studies 10(9-19):53-71(19). http://www.ingentaconnect.com/content/imp/jcs/2003/00000010/F0020009/art00005

Zajonc, R. B. (1965) Social facilitation. Science 149(3681):269-74. http://dx.doi.org/10.1126/science.149.3681.269

Zaki, J. \& Ochsner, K. (2009). The need for a cognitive neuroscience of naturalistic social cognition. Annals of the New York Academy of Science 1167, 16-30

Zwickel, J. \& Vo, M. L. (2010) How the presence of persons biases eye movements. Psychonomic Bulletin \& Review 17(2):257-62. http://dx.doi.org/10.3758/PBR.17.2.257 


\section{Funding sources}

LS, BT \& TS were supported by the VolkswagenFoundation ("Being Adressed as You: Empirical and Conceptual Investigations of a Second-Person Approach to Other Minds"). LS was also supported by the Koeln Fortune Program of the Medical Faculty at the University of Cologne. BT was also supported by a EU FP7 stipend (Marie Curie Action-IEF 237502 "Social Brain: How does our brain learn to be social"). TS was also supported by the German state of Northrhine-Westfalia. KV was also supported by the VolkswagenFoundation and by the German Ministery of Research and Education ("Social Gaze”, 01 GW 0611; “Other Minds”, 01 GP 0802).

\section{Acknowledgements}

LS wishes to acknowledge the various and significant contributions of colleagues in the Departments of Psychiatry and Neurology at the University Hospital Cologne, the Institute of Neuroscience and Medicine at the Research Center Juelich and the Department of Social Psychology at the University of Cologne to the empirical studies presented in this article, in particular, Simon B. Eickhoff, Bojana Kuzmanovic and Marcus Wilms. Furthermore LS is thankful to Guillaume Dumas and Denis A. Engemann for stimulating discussions. 